\title{
Dada, Tzara und die sinnhafte Macht des Nonsens
}

Die Problematik des Nonsens spielt in Alfred Jarrys Stücken eine nicht minder wichtige Rolle als jene konkrete Theatralität, mithin Körperlichkeit und Vergänglichkeit des Dargestellten, die gleichsam den eigentlichen Text überwuchern und eine Tendenz zur reinen Performanz aufweisen. Sie wird uns nicht nur bei Jarry und der Entwicklung hin zum absurden Theater, sondern auch in einer ganz entscheidenden künstlerischen und avantgardistischen Bewegung bewusst werden, deren verbindende Funktion aus heutiger Perspektive evident ist. Denn sie stellt gleichsam die Brücke dar zwischen dem frühen Avantgardismus - zum Teil auch avant la lettre - des italienischen wie europäischen Futurismus und des futuristischen Theaters in der Traditionslinie von Ubu Roi einerseits und der entwickelten Avantgarde, man könnte fast sagen ,Hoch-Avantgarde‘, des französischen Surrealismus andererseits. Ich spreche selbstverständlich vom Dadaismus und den Dadaisten!

Während der Futurismus zunächst eine Vorkriegserscheinung war, die in den Krieg hineinwuchs und ihn als Spektakel herbei sehnte, ist Dada in gewisser Weise eine Kriegserscheinung, die freilich eine gänzlich andere Position gegenüber Krieg und organisierter Gewalt einnahm. Während der Futurismus sich für den Krieg engagierte und Italien erfolgreich mit hinein reißen sollte, entwickelte Dada von Zürich aus eine klar gegen alle kriegerische Gewalt propagandistisch vorgehende Position, die zu Beginn des Ersten Weltkrieges angesichts der allgemeinen Begeisterung noch die Position politischer Außenseiter war. Dada und der sich herausbildende Dadaismus agierten und agitierten von einem Territorium aus, das nicht in den Ersten Weltkrieg, in die „Grande Guerre“, hineingezogen worden, sondern neutral geblieben war: So bildete die Schweiz den idealen Nährboden für die Entwicklung dieser künstlerisch-literarischen Bewegung gegen den Krieg, gegen alle Kriege.

Wir hatten bereits bei Kurt Schwitters im Anti-Liebesgedicht An Anna Blume bemerkt, dass in ganz entscheidender Weise die Erfahrungen der Futuristen mit den sogenannten „befreiten Worten“ genutzt und umgesetzt wurden bei dem Versuch, die Sprache zunehmend aus der traditionellen Logik herauszulösen, die Syntax zu unterlaufen, die Hierarchien im Satzbau abzubauen und die Semantik zu entstellen. Klar ist dabei, dass Konventionen und Traditionen nicht allein im literarischen Kontext, sondern im Bereich der allgemeinen und alltäglichen Sprache selbst angegriffen und überwunden werden sollten. Die logisch fundierte Sprache war also ein Feind, vielleicht sogar der Feind schlechthin: Wer mit der bürgerlichen Gesellschaft ein für alle Mal brechen wollte, der musste ran an die Sprache und sie verstellen, der musste zu einem Sprachendieb werden und sein Beutegut beherzt gegen alle Wiedereingliederungsversuche verteidigen! 
Betrachten wir den Dadaismus als eine viellogische und nicht zentrierte Gemeinschaft und Bewegung, die ihre unterschiedlichen Filialen und sehr verschiedenartige Spielarten besaß, so galt für ihn doch insgesamt: Angriffsgegenstand des Dadaismus war nicht nur die Kunst, sondern die gesamte Gesellschaft überhaupt. Mit ihr galt es zu brechen, sie war zu zerstören, koste es, was es wolle!

Schon 1944, also noch während des Zweiten Weltkrieges, hat Maurice Nadeau in seinem frühen und klugen Buch über die Geschichte des (französischen) Surrealismus auf die Tatsache aufmerksam gemacht, dass die Erfahrung des Krieges von grundlegender Bedeutung für die Veränderungen des surrealistischen Weltbildes war. Ein ungeheuer blutiger, sinnloser Krieg war geführt worden um die Verschiebung kleinster Grenzziehungen in Europa, um einander bestimmte Kolonien etwa in Afrika abzujagen und um schließlich einen Zustand zu erreichen, in dem die Sieger über kaum bessere wirtschaftliche und soziale Verhältnisse verfügten als die von ihnen Besiegten. Die ganze Absurdität und Sinnlosigkeit dieses Krieges, den die Faschisten und die Futuristen, aber auch alle Nationalisten und Chauvinisten Europas so sehr herbeigesehnt hatten, war 1916 bereit offenkundig. Es war die Stunde von Dada! Aber worum ging es? Sollte einfach ein logischer Gegen-Diskurs gegen den kriegsbegründenden Diskurs, sollte einfach eine strukturell vergleichbare akratische Position gegen die enkratischen Mächte ins Feld geführt werden? War es überhaupt noch möglich, der absoluten Sinnlosigkeit sinnvolle Sätze entgegenzustellen und auf argumentative Fortschritte zu hoffen? War all das nicht längst versucht worden?

Glauben Sie mir: Das sind grundlegende Fragen und sie sind grundlegend bis in unsere Zeit! Denn unsere offenen Gesellschaften sind heute wieder oder erneut gefährlich vereinfachenden Diskursen ausgesetzt, die von cleveren Menschen ersonnen werden, damit die Dummen diese einfachen Angebote übernehmen. „Bei meiner grünen Kerze: Jawoll“, hätte König Ubu gesagt. Verkürzt gesagt stellt sich eine grundlegende Frage: Wie kann man Dummköpfe überzeugen? Wie lassen sich die Anhänger von Populismen jeder Couleur noch erreichen und von ihrer Begeisterung für die so simplen Anliegen ihrer Führer, für die so einfachen Lösungen ihrer Heilsbringer abhalten? Viele Künstler Europas begriffen, dass ein anderer Weg gesucht werden musste, der nicht argumentativen Zuschnitts sein konnte. Denn die meisten Faschisten, Chauvinisten oder Nationalisten jeglicher Ausrichtung lassen sich nicht einfach argumentativ überzeugen: Ihnen muss etwas Anderes, Weiteres entgegengesetzt werden.

Im Bereich der Politik, der Philosophie, der Wissenschaft und vielen anderen wissenschaftlichen und nicht-wissenschaftlichen Feldern verwandelte sich zunehmend die Einsicht in die Absurdität des anhaltenden Stellungskrieges auch in Gegenvorschläge reformierender oder revolutionärer Art, die sich je- 
weils ganz spezifischen Aspekten der Gesellschaft zuwandten. Dagegen war es für die Künstler als Spezialisten der Farbe, der Formen, der Bühne oder im Bereich der Literatur - der Sprache lange schon evident, dass die Sprache selbst angegriffen werden musste. Denn es war eben jene Sprache, in welcher die ganze Kriegsrhetorik dröhnte, jene Sprache also, die all das Unheil verschuldet hatte, in der die unterschiedlichsten Verbrechen, mithin der Kolonialismus, der Imperialismus, die Zerstörung einer ganzen Generation, die Ausbeutung ganzer Völkerschaften ausgeführt worden waren. Doch wie war all dies zu stoppen, um der Vernichtung immer größerer Menschenmassen wirkungsvoll und nachhaltig Einhalt zu gebieten?

Die Lösung sahen einige der Künstler in dem breit angelegten Versuch, eben jenes Vehikel zu beseitigen, um auf seinen Ruinen eine neue Sprache zu errichten. So sollte jener Kanal der menschlichen Kommunikation ausgemerzt und radikal transformiert werden, der das ganze Übel der Massenvernichtung überhaupt erst möglich gemacht hatte. Auf diese Weise lässt sich die von den Futuristen teilweise übernommene, unzweifelhaft aber nun radikalisierte und mit einer anderen, ja umgekehrten Zielsetzung versehene Entstellung der Sprache begreifen, die in ihrer Wucht sehr wohl mit dem Krieg selbst verglichen werden kann, mit einem wahren Krieg gegen die Sprache der Vernichtung, die nun selbst der Vernichtung preisgegeben werden sollte. Es galt, eine radikale, eine revolutionäre Veränderung der bürgerlichen Gesellschaft entschlossen voranzutreiben und mit den Kriegstreibern Schluss zu machen.

Prägnante Beispiele für diese konstruktive, zielgerichtete Zerstörungsarbeit sind die Gedichte und Arbeiten von Kurt Schwitters, die bis hin zur Auflösung in reiner Phonetik gehen und höchstens noch Restbestände traditioneller Semantik bestehen lassen. Es ist eine Zerstörung der Sprache, gewiss, aber zugleich handelt es sich um eine Zerstörungsarbeit, die auch - wie wir sahen - eine Arbeit konstruktiver Art ist, macht sie doch Dinge hörbar, denkbar und sagbar, die zuvor nicht hätten realisiert beziehungsweise ausgesprochen werden können. Denn bis heute, und die Reaktionen der Zuhörerschaft zeigen dies, scheint das pure Lautgedicht nicht nur in der Form der Ur-Sonate eine provozierende und vielleicht mehr noch schockierende Wirkung auf sein Publikum zu haben, entzieht es sich doch dem, was alle Zuhörerinnen und Zuhörer vom Künstler im Grunde einfordern: Sinn zu machen.

Wir beginnen aus dieser Perspektive bereits zu verstehen, welcher Sinn hinter dem Nicht-Sinn, dem Un-sinn, dem „Nonsense“ steckt, wie der Nonsens folglich selbst wiederum Sinn machen, Sinn erzeugen kann. Mehr noch: Wir begreifen, wie in einer sinnentleerten, sinnlos gewordenen Welt des Weltkriegs der Nonsense die künstlerisch vielleicht überzeugendste Art und Weise ist, dem Unsinnigen und Sinnlosen massiver Vernichtung von Leben etwas entgegenzuhalten, 
was dieser Unsinnigkeit trotzen kann. Denn eine regelrechte und regelgerechte Sinnverweigerung kann sehr wohl Sinn hervorbringen - gerade auch durch die Negierung jeder traditionellen Semantik.

Die Radikalität der Gegenpositionen gegenüber dem noch immer vorherrschenden gesellschaftspolitischen und ökonomischen, aber auch künstlerischen und literarischen System wird im Dadaismus schon von Beginn an deutlich, zeigt sich aber auch noch bei Vertretern des Dadaismus, die sich der von der Schweiz ausgehenden Bewegung etwas später anschlossen. Dies war etwa in Frankreich der Fall, wo sich erst mit einer gewissen Verspätung der Dadaismus konstituieren, festsetzen und entwickeln konnte, zumal man von Dada in Zürich zunächst wenig wusste.

Ich möchte Ihnen daher eine Passage aus einem Manifest von Louis Aragon vorlegen, jenem großen französischen Lyriker, Romancier und Intellektuellen, der in seiner persönlichen Entwicklung im Grunde zentrale Entwicklungsmomente des Surrealismus markierte. Louis Aragons Weg führte von der frühen Orientierung an Dada über die künstlerische Entfaltung des Surrealismus bis hin zur politischen Ausrichtung an der Kommunistischen Partei Frankreichs, an der Louis Aragon freilich selbst dann noch festhielt, als alle anderen Surrealisten längst dem einst machtvollen PCF die Gefolgschaft aufgekündigt hatten. Aragon folgte seiner Partei selbst dann noch, als die berüchtigten Schauprozesse Stalins wahre Austrittswellen linker westeuropäischer Intellektueller provozierten.

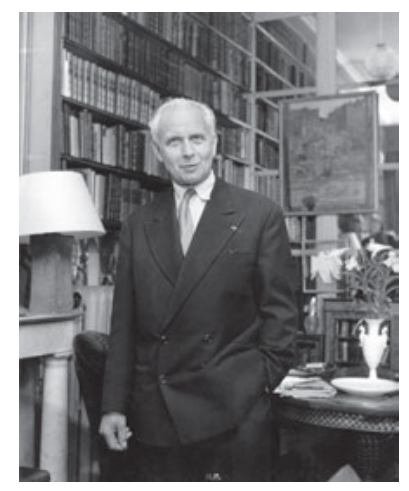

Abb. 44: Louis Aragon (Paris, 1897 - ebda., 1982).

Aragons Ablehnung des Bestehenden war in seinen frühen Jahren total. Daher versteht man seine spätere Hoffnung vielleicht etwas besser, eine Hoffnung, die er auf das kurze Zeit zuvor entstandene und damals noch immer in Entstehung begriffene neue Reich der Sowjetunion unverbrüchlich setzte. Die Geste der Zerstörung war bei dem jungen Intellektuellen im Jahr 1919 unverkennbar; an einem 
jener Dada-Abende, die als Bürgerschreck-Spektakel aufgezogen wurden und oftmals in handgreiflichen Tumulten endeten. Wir verstehen, dass sich in diesem Fall die Dadaisten durchaus einer Tradition anschlossen und bedienten, welche in den Zirkeln der Futuristen üblich war und die zweifellos über lange Jahre ein Markenzeichen der historischen Avantgarden darstellte. Doch wir hatten auch gesehen, dass diese tumultartigen Szenen bereits bei der Uraufführung von Alfred Jarrys Ubu Roi an der Tagesordnung waren - denn nicht umsonst begehrte die Zuschauerschaft im Theater gegen eine verbreitete Publikumsbeschimpfung und die Zurschaustellung schockierender Bühnenereignisse auf.

An jenem lauschigen Abend des Jahres 1919 also hatte man das Publikum insoweit getäuscht und angelockt, als man vorgab, Charlie Chaplin in Paris zu präsentieren. Aber nix war's mit Charlie Chaplin! Stattdessen wurden die zahlreich herbeigeströmten Zuschauerinnen und Zuschauer mit Dutzenden von Manifesten und Proklamationen konfrontiert und förmlich beworfen, worauf sich das Publikum seinerseits von seinem Schock erholte und insofern rächte, als man die auftretenden Literaten fleißig beschimpfte und mit allem, was man zur Verfügung hatte, bewarf. Doch sehen wir uns einen Ausschnitt aus diesem Manifest des Lyriker Louis Aragon einmal näher an:

Keine Gemälde mehr, keine Literaten mehr, keine Musiker mehr, keine Bildhauer mehr, keine Religionen mehr, keine Republikaner mehr, keine Königstreuen mehr, keine Imperialisten mehr, keine Anarchisten mehr, keine Sozialisten mehr, keine Bolschewiken mehr, keine Politiker mehr, keine Proletarier mehr, keine Demokraten mehr, keine Armeen mehr, keine Polizei mehr, keine Vaterländer mehr, es ist jetzt Schluss mit all diesen Dummheiten, nichts mehr, nichts mehr, nichts, NICHTS, NICHTS, NICHTS.

Auf diese Weise hoffen wir, dass sich die Neuheit, welche dieselbe Sache ist wie all das, was wir nicht mehr wollen, weniger verdorben durchsetzen wird, weniger unmittelbar GROTESK. ${ }^{1}$

Diese Passage aus Louis Aragons Manifest zeigt nicht nur, wie weit der junge Schriftsteller damals noch von der Hoffnung auf den Bolschewismus entfernt und wie nahe er an deutlich nihilistischen Positionen war, sondern sie führt auch die ganze Wut auf die bestehenden Strukturen innerhalb wie außerhalb der Kunst vor. Gewürzt ist sie natürlich mit jenem Geist performativer, wir könnten auch sagen: ostentativer Zerstörungswut, welche die Dadaisten von Beginn an auszeichnete. Zugleich sehen wir und hören wir natürlich auch, dass diese Verdammungsorgie selber wieder rhythmisiert ist, fast die Struktur eines Gedichts in freien Versen

1 Aragon, Louis: Manifeste du mouvement Dada. In: Littérature (Paris) 2e année, No 13 (Mai 1920): Vingt-trois manifestes du mouvement Dada, S. 1. 
besitzt, mit einer Vielzahl von Reimen, Alliterationen, semantisch konsequenten Abfolgen und einer zu Grunde liegenden Argumentation. Aragons Text nimmt folglich selbst literarische Strukturen an, ohne freilich in bestehende Traditionen zu verfallen - auch wenn der Dadaismus wider Willen selbst rasch eigene Traditionen schuf, die wiederum Modellcharakter besaßen. Denn der Dadaismus tat dies sehr wohl, trotz der ständigen Zerstörungswut seiner Hauptfigur Tristan Tzara, der sein Hauptaugenmerk nicht nur auf die Destruktion des Bestehenden, sondern auch auf jene des Angriffs selbst richtete.

Damit ging Tristan Tzara durchaus einen Schritt weiter als Louis Aragon in der angeführten Passage. Doch in Frankreich hatten sich längst unabhängig vom Dadaismus eigenständige Entwicklungslinien herausgebildet, welche - gerade auch mit Blick auf die spätere Entfaltung des französischen Surrealismus - unverkennbare Affinitäten zu Dada Zürich aufwiesen, das doch einige Jahre früher aufgeblüht war. In dieser Zeit der großen Ismen gab es überall Sonderentwicklungen und sehr eigenständige Interpretationen avantgardistischer Verfahren, welche zugleich die Vielfalt und unbestreitbare Einheit der historischen Avantgarden belegten.

So schrieb etwa Jacques Vaché, ein Autor, der für den jungen André Breton von großer Wichtigkeit war, in seinen 1919 publizierten Lettres de Guerre eine totale anklage der Kunst und Literatur nieder, eine Anklage, die im Grunde die Kunst ähnlich wie die Gesellschaft in den Orkus des Absurden und zu Zerstörenden verwies. Vaché vertrat damit eine zerstörerische, den Bruch mit allem Vorhandenen akzentuierende Position, welche er übrigens nur in Hinblick auf einen einzigen Künstler nuancierte. Und dieser Künstler war kein anderer als der Theatermann und Romancier Alfred Jarry, der mit seinen künstlerischen Praktiken und Verfahren ja gerade die herrschende Kunst- und Literaturauffassung zu unterspülen gesucht hatte. Schauen wir uns eine kurze Passage von Jacques Vaché einmal an:

\footnotetext{
Wir lieben weder die Kunst noch die Künstler (nieder mit Apollinaire) ... wir ignorieren Mallarmé ganz ohne jeden Hass, aber tot ist er. Wir kennen keinen Apollinaire mehr - DENN wir verdächtigen ihn, allzu wissentlich Kunst zu machen, Romantik mit Telefondraht zusammenzufummeln und dabei nicht zu wissen, was ein Dynamo ist. DIE STERNE wieder herunterzuholen! - wie langweilig das ist - und dann sprechen sie dabei doch bisweilen ernsthaft! Ein Mann, der glaubt, ist seltsam. ABER DA EINIGE NUN MAL ALS SCHMIERENSCHAUSTELLER AUF DIE WELT GEKOMMEN SIND ...
}

2 Vaché, Jacques: Lettres de Guerre. Zit. nach Nadeau, Maurice: Histoire du surréalisme (1945). Paris: Seuil 1964, S. 24. 


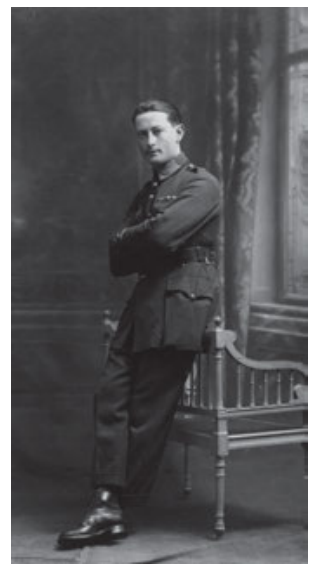

Abb. 45: Jacques Vaché (Lorient, 1895 - Nantes, 1919).

Wir konstatieren nicht ohne eine gewisse Verblüffung, dass hier sogar mit Apollinaire gebrochen wird, der doch innerhalb der französischen Traditionslinie der Avantgardisten und insbesondere der Surrealisten um André Breton eine Art Fixstern darstellte, an dem man sich orientieren konnte. Apollinaire, der eine Scharnierfunktion übernommen hatte zwischen der literarischen Tradition des 19. Jahrhunderts in ihren wegweisenden Aspekten und der von den Surrealisten intendierten neuen Verfasstheit und des neuen Ortes der Kunst innerhalb der Gesellschaft. Auch Stéphane Mallarmé wird dem Tod und dem Vergessen anheim gegeben, der doch gerade für die neo-avantgardistischen Strömungen der zweiten Hälfte des 20. Jahrhunderts eine so fundamentale Funktion übernehmen sollte. Mit alledem soll gebrochen werden: All dies soll nunmehr zu Ende sein, um Platz für einen Neuanfang zu schaffen.

Entscheidend an dieser Schelte von Jacques Vaché ist, dass der Kunst wie den Künstlern, der Literatur wie den Literaten das Daseinsrecht entzogen wird, um ein für alle Mal die Tradition zu kappen - in einer Radikalität, wie sie die Neo-Avantgarden in der Tat nicht mehr zu fordern in der Lage waren. Denn die neo-avantgardistischen Strömungen konnten längst nicht mehr mit derselben Vehemenz einen Neuanfang einfordern, schon allein aus dem Grund, dass diese Forderung vor ihnen bereits erhoben worden und dadurch gleichsam historisch geworden war. An diesem Punkte mag deutlich werden, dass die historischen Avantgarden all ihrer Zerstörungswut zum Trotz sehr wohl eine literar- und kunstästhetische Tradition schufen, mit welcher die Literat*innen und Künstler`innen ab der zweiten Hälfte des 20. Jahrhunderts leben mussten. Diese Tradition des Traditionsbruches ließ sich nicht so einfach ignorieren oder wegdiskutieren. Wir haben es hier mit eben jenem Phänomen zu tun, welches wir im Eingangsteil unserer Vorlesung am Beispiel des spanischen Schriftstellers Enrique Vila-Matas in aller Deutlichkeit 
an seinem Umgang mit der historischen wie der Neo-Avantgarde aufgezeigt und gesehen hatten.

Diese beiden Zitate, die ich Ihnen kurz vorlegen wollte, um Ihnen zu zeigen, dass es auch außerhalb des eigentlichen Dadaismus parallele Entwicklungen gab, welche zu ähnlichen Konsequenzen gerade aus der Erfahrung der Absurdität des Kriegs gekommen waren, sollten uns lediglich als erste atmosphärische Annäherungen an den Dadaismus oder - wie wir vielleicht besser sagen könnten an Dada dienen. Denn die Bezeichnung „Dada“ steht für eine Bewegung, die gleichsam aus dem Nichts sich zu entwickeln schien, aus jener neutralen (und noch marginalen) Schweiz, um deren Grenzen herum der Erste Weltkrieg tobte. Es wäre nicht leicht vorauszusagen gewesen, dass eine große internationale Künstlerbewegung just in jener Schweiz entstehen würde, die sich klug aus den zerstörerischen Kriegswirren heraushielt und wo sich nun Menschen aus aller Herren Länder trafen, die aus den verschiedensten Gründen hier Zuflucht suchten beziehungsweise gestrandet waren.

Für die Eidgenossenschaft waren dies wichtige Jahre. Denn schon wenige Jahre später trafen sich in Genf die unterschiedlichsten Vertreter fast aller damaligen Nationen, um nach den schrecklichen Erfahrungen des Ersten Weltkriegs jenen Völkerbund oder auf Französisch jene „Société des Nations“ zu gründen, die den Zweiten Weltkrieg zwar nicht aufhalten konnte, aber doch zu einem Vorbild für die aktuellen Vereinten Nationen wurde. Gewiss, auch die Vereinten Nationen sind mit weiter gehenden Vollmachten ausgestattet, aber ähnlich wie der Völkerbund leider noch immer nicht in der Lage, im Sinne Immanuel Kants sich weltweit zu vereinigen und den „ewigen Weltfrieden“ herzustellen. Wir werden dieses Genf der Nachkriegszeit des Ersten Weltkriegs noch im nächtlichen Licht eines avantgardistischen Textes von Albert Cohen näher kennenlernen. Innerhalb dieses historischen Kontexts sei jedoch auf die Entstehung von Dada im nahegelegenen Zürich hingewiesen und damit auf jenes Ur-Dada, von dem aus sich die Bewegung in verschiedenste Winde zerstreute, um sich dann wieder an einigen wenigen Orten - insbesondere in Berlin, New York oder Paris - in verschiedenartiger und zum Teil gegensätzlicher Weise zu konzentrieren.

In Zürich begannen die Dinge zunächst ganz regionalistisch, auch wenn die einzelnen Mitglieder der neuen Bewegung aus allen Himmelsstrichen Europas zusammenkamen. Dem Eröffnungs-Manifest des in die Schweiz emigrierten deutschen Schriftstellers Hugo Ball ist die regionale Verankerung und der tiefe Abscheu vor der blutig ablaufenden Weltgeschichte überdeutlich anzumerken. Beschäftigen wir uns kurz und exemplarisch mit einigen Biographemen aus dem Leben von Hugo Ball!

Der als Sohn eines Schuhfabrikanten in Pirmasens am 22. Februar 1886 geborene Hugo Ball wurde streng katholisch erzogen und studierte nach dem 
Abitur von 1906 bis 1910 Germanistik, Geschichte und Philosophie an den Universitäten von München und Heidelberg. Wieder stoßen wir auf Friedrich Nietzsche; doch Balls Dissertation über den deutschen Philosophen wurde nicht eingereicht, sondern erschien postum. Ball arbeitete als Regisseur in Dresden und an den Münchner Kammerspielen. Sein enger Kontakt zur Avantgarde in Theater und Kunst führte ihn 1913 in das Zentrum des literarischen Expressionismus nach Berlin. Nach der Besichtigung belgischer Kriegsschauplätze wurde Hugo Ball entschiedener Pazifist und emigrierte 1915 mit seiner späteren Ehefrau, der Schauspielerin Emmy Hennings, in die neutrale Schweiz, wo er als freier Künstler zum Teil unter schwierigen Verhältnissen arbeitete.

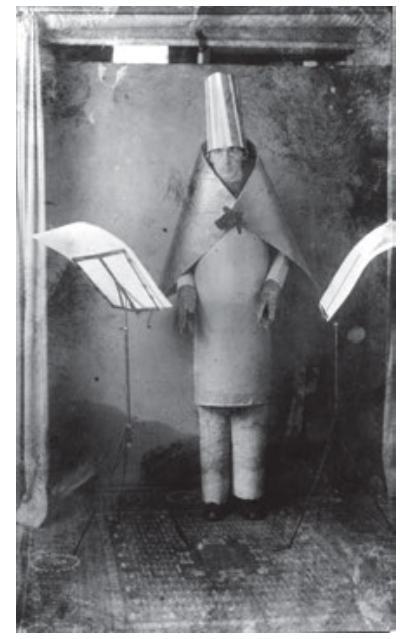

Abb. 46: Hugo Ball (Pirmasens, 1886 - Sant'Abbondio in der Schweiz, 1927).

In Zürich war Ball Mitbegründer des Künstlerlokals Cabaret Voltaire, das am 5. Februar 1916 eröffnete und Ende Juni/Juli 1916 bereits wieder geschlossen wurde. Trotz dieser nur kurzen Zeitdauer wurde das Voltaire zum Hotspot der dadaistischen Bewegung: Hier kam es zur Aufführung berühmter Lautgedichte und kleiner Vorstellungen, in denen Hugo Ball brillierte. Sie wollen eine kleine Kostprobe? Hier sein Lautgedicht KARAWANE:

jolifanto bambla ô falli bambla

grossiga m'pfa habla horem

égiga goramen

higo bloiko russula huju

hollaka hollala

anlogo dung

blago bung

blago bung 


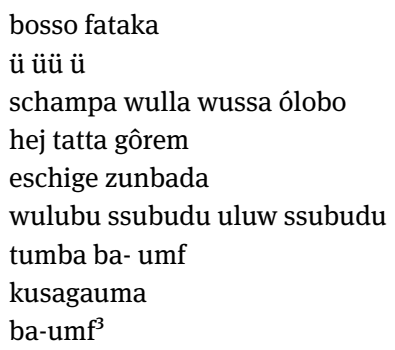

So, das mag als Kostprobe genügen: Bitte stellen Sie sich dieses Gedicht in unterschiedlichen Schrifttypen, Kursivschriften und Fettdrucken vor; und machen Sie sich ihren eigenen Reim darauf! Sie verstehen jetzt vielleicht nochmals besser, was ich mit dem Begriff „Nonsense“ ungleich Un-Sinn in Kunst und Literatur gemeint habe: Das Gedicht ist eine offene Kampfansage an jegliche eindeutige Sinnzuweisung. Doch zurück zu unserer Kurzbiographie!

Neben Tristan Tzara, Richard Huelsenbeck, Marcel Janco und Hans Arp avancierte Hugo Ball zum Hauptvertreter der dadaistischen Bewegung. Nach seiner Mitgestaltung der Galerie Dada in Zürich arbeitete er ab September 1917 in Bern für Die freie Zeitung bis zu deren Einstellung im Jahr 1920. Seitdem lebte er, meist unter schwierigen ökonomischen Bedingungen, im Tessin, zeitweilig zu Studienaufenthalten auch in Italien.

Hugo Ball wurde wegen seiner Rückwendung zum Katholizismus im Sommer 1920 und seiner radikalen Kritik an der preußisch-protestantischen Tradition der deutschen Geistesgeschichte zu Lebzeiten angegriffen und über lange Zeit kaum gewürdigt. Sein vielschichtiges Werk umfasste Gedichte und mehrere Romane, aber auch eine Biographie Hermann Hesses, zahlreiche Essays sowie autobiographische Aufzeichnungen. Seinen Ruhm als Schriftsteller begründeten aber vor allem seine dadaistischen Gedichte, die ihn nicht zuletzt als einen Pionier des Lautgedichts präsentierten. Er verstarb am 14. September 1927 in Sant'Abbondio in der Schweiz.

In seinem Manifest am ersten Dada-Abend in Zürich, der programmatisch am 14. Juli 1916 stattfand, also am Tag der Französischen Revolution und damit im damaligen Bewusstsein der ,Mutter aller Revolutionen', verweist Hugo Ball zunächst auf die Herkunft des Wortes „Dada“. Es sei gleichsam ein Zufallsprodukt, das in einer einschlägigen Enzyklopädie durch Zufallssuche gefunden wurde und in den unterschiedlichsten Sprachen jeweils etwas anderes bedeute.

3 Ball, Hugo: Karawane (1917). In Huelsenbeck, Richard: Dada Almanach. Berlin: Erich Reiss Verlag 1920. S. 53. 
Hugo Ball zog daraus die künstlerischen Konsequenzen. Auch die Gastfreundschaft der Schweiz ließ Ball im Übrigen nicht unerwähnt, eine wichtige Verortung dieses international entstandenen Züricher Manifests des Cabaret Voltaire:

Ein internationales Wort. Nur ein Wort und das Wort als Bewegung. Es ist einfach furchtbar. Wenn man eine Kunstrichtung daraus macht, muß das bedeuten, man will Komplikationen wegnehmen. Dada Psychologie, Dada Literatur, Dada Bourgeoisie und ihr, verehrteste Dichter, die ihr immer mit Worten, nie aber das Wort selber gedichtet habt. Dada Weltkrieg und kein Ende, Dada Revolution und kein Anfang. [...]

Ich lese Verse, die nichts weniger vorhaben als: auf die Sprache zu verzichten. Dada Johann Fuchsgang Goethe. Dada Stendhal. Dada Buddha, Dalai Lama, Dada m'dada, dada m'dada, Dada mhm'dada. Auf die Verbindung kommt es an, und dass sie vorher ein bißchen unterbrochen wird. Ich will keine Worte, die andere erfunden haben. Alle Worte haben andere erfunden. Ich will meinen eigenen Unfug, und Vokale und Konsonanten dazu, die ihm entsprechen. [...]

Da kann man nun so recht sehen, wie die artikulierte Sprache entsteht. Ich lasse die Laute ganz einfach fallen. Worte tauchen auf, Schultern von Worten; Beine, Arme, Hände von Worten. Ay, oi, u. Man soll nicht zuviel Worte aufkommen lassen. Ein Vers ist die Gelegenheit, möglichst ohne Worte und ohne die Sprache auszukommen. Diese vermaledeite Sprache, an der Schmutz klebt wie von Maklerhänden, die die Münzen abgegriffen haben. Das Wort will ich haben, wo es aufhört und wo es anfängt. [...]

Warum kann der Baum nicht Pluplusch heißen, und Pluplubasch, wenn es geregnet hat? Und warum muß er überhaupt etwas heißen? Müssen wir denn überall unseren Mund dran hängen? Das Wort, das Wort, das Weh gerade an diesem Ort, das Wort, meine Herren, ist eine öffentliche Angelegenheit ersten Ranges. ${ }^{4}$

In diesem ersten, zweifellos gemäßigten Dada-Manifest vom ersten Dada-Abend in Zürich - die futuristischen ,serate futuriste“ lassen grüßen - zeigt bereits, wohin die Post abgeht. Die gesellschaftskritische Stoßrichtung ist unübersehbar und die fundamentale Kritik am Vehikel der bürgerlichen Gesellschaft, an der Sprache also, ist ein von den Futuristen ererbtes, aber dadaistisch zugespitztes Ingredienz. Man könnte sagen, dass dieser Kriege führenden Gesellschaft die Sprache entzogen werden soll, jene Sprache, die stets die anderen erfunden haben und die - um ein Wort Nietzsches zu gebrauchen - in uns spricht, die uns spricht (und nicht wir sie). Denn der deutsche Philosoph hatte bereits die Frage gestellt - und Heidegger wie Lacan und Derrida nach ihm: Wer spricht? Wer spricht, wenn ich spreche? Was spricht mich?

Hugo Ball, der seine Doktorarbeit über Nietzsche in Basel nicht eingereicht hatte, aber ganz offenkundig ein Nietzsche-Experte war, gibt hierauf eine zer-

4 Ball, Hugo: Eröffnungs-Manifest. In: Asholt, Wolfgang / Fähnders, Walter (Hg.): Manifeste und Proklamationen, S. 121. 
störerische und schöpferische Antwort zugleich, insofern die Worte der anderen zerstört werden sollen, an ihre Stelle eigene Worte treten können, die Worte aber auch ganz ausradiert werden müssten. Denn an den Worten klebt der Schmutz, der ganze Dreck dieser Gesellschaft, wobei Hugo Ball nicht einmal explizit auf den Krieg, der in dieser historischen Situation von 1916 allgegenwärtig ist, aufmerksam zu machen braucht. Es genügt, auf die Schweiz zu verweisen, auf die Dimension des Geldes und schließlich auch auf den Weltkrieg, der nicht enden und die Revolution, die nicht beginnen will. Der Bruch mit der alten Macht, mit den alten Mächten muss kommen; aber wo ist eine Revolution in Sicht? Wo ist sie möglich? Und warum nicht hier und jetzt?

Es ist eines der signifikantesten Zeichen der Zeit, dass die ,wahre‘ Revolution der Politik schon auf dem Wege war, und zwar just von Zürich aus. Sie wird ihr erstes gigantisches Fanal kaum ein Jahr später eben nicht in den westeuropäischen Gesellschaften - wie noch Karl Marx prognostiziert hatte - errichten, sondern in Russland, in der Sowjetunion, mit der Oktoberrevolution des Jahres 1917. Lenin und Tzara sind in der Tat grundverschieden orientiert, und doch ist der Wille zum Bruch, der Wille eines Bruchs mit dieser besudelten Gesellschaft und Zivilisation, bei beiden Männern mit demselben Hass, derselben Leidenschaft, derselben Ausdauer gepaart. „We want it all and we want it now!“ Der Weltkrieg sollte enden und die Revolution endlich beginnen!

Doch für die beiden Anführer einer sich als künstlerisch und einer sich als politisch verstehenden Avantgarde sollte bei aller Konzentration auf ein Land noch längst nicht die Weltrevolution aus den Augen verloren werden. So verwundert es auch nicht, dass bei der ersten Manifestation von Dada überhaupt, in der Erklärung von Richard Huelsenbeck, vorgetragen im Cabaret Voltaire im Zürich des Frühjahrs 1916, der dadaistische Diskurs einsetzt mit einer provokativen Formel, deren parodierten Bezugspunkt wir alle kennen: „Edle und respektierte Bürger Zürichs, Studenten, Handwerker, Arbeiter, Vagabunden, Ziellose aller Länder, vereinigt euch.“5

In derlei Formulierungen spielt die künstlerische Avantgarde mit der politischen Avantgarde, mit dem Manifest des Kommunismus und der Kommunistischen Internationale. In der Fortführung dieser Beziehung wird der junge André Breton einige Jahre später nach dadaistischem Vorbild eine Surrealistische Internationale nach Paris einberufen. So gab es stets den Versuch, die künstlerische mit der politischen Avantgarde zu verschmelzen. Dada war zweifellos eminent politisch, und dies von Beginn an - auch wenn die verschiedenen Teile

5 Huelsenbeck, Richard: Erklärung. In: Asholt, Wolfgang / Fähnders, Walter (Hg.): Manifeste und Proklamationen, S. 117. 
der Bewegung sich in Europa relativ rasch auseinanderdividierten. Dabei war diese politische Ausrichtung aber weitgehend jener des italienischen Futurismus entgegengestellt - und dies zu einem Zeitpunkt, als die italienischen Futuristen noch immer, wenn auch nun wieder stärker auf Italien zurückgeworfen, an ihren Manifesten und Proklamationen schrieben. Doch Dada richtete sich ebenso gegen jede Form von Kriegstreiberei wie gegen alle Formen eines Faschismus, dessen Bedrohung für Europa sich von Italien ausgehend langsam abzuzeichnen begann. War der Beginn der historischen Avantgarden im Zeichen des Futurismus deutlich faschistoid, so wandte sich Dada ganz entschieden gegen derlei rechtsorientierte politische Ausrichtungen und schuf eine Plattform für Avantgardisten, die nicht für, sondern gegen die verschiedensten Faschismen zu agitieren suchten.

Die politische Dimension des futuristischen Treibens war vielen Avantgardisten sehr bewusst. Eben deshalb spaltete sich nun die historische Avantgarde in verschiedene Lager, wobei sich sagen ließe, dass in all diesen Lagern eine spezifisch politische Stoßrichtung vorhanden war, selbst wenn sie sich nicht immer deutlich artikulierte. Gegen die Kriegseuphorie des italienischen Futurismus regte sich in anderen nicht nur europäischen Ländern selbst bei verschiedenen Futuristen Widerstand. So schrieb bereits im Herbst 1914 Viktor Chovin:

Ich fürchte, naiv zu wirken, aber ihm, Marinetti, dem Herold des italienischen Futurismus, bin ich bereit, eine verhängnisvolle Rolle im Weltkrieg zuzuschreiben, der Europa mit dem Rauch niedergebrannter „ehrwürdiger“ Städte und „ehrwürdiger“ Museen einhüllte.

Ich fürchte, naiv zu wirken, aber mich dünkt, dass dieser Marinetti, oder wenn nicht er selbst, so der Marinettist preußischen Sinnes mit der Pickelhaube des deutschen Leutnants den Haufen Vandalen führte, der Löwen in Brand setzte. Bombardierte nicht er die Kathedrale von Reims und warf nicht er, der Spezialist der Flugzeugbranche, Bomben auf die Kathedrale Notre Dame von Paris? ${ }^{6}$

Diese Einschätzungen haben sicherlich eine Vielzahl von guten Gründen für sich, wenn man Marinetti auch zweifellos nicht für den Krieg selbst verantwortlich machen kann. Aber die Bombardierung von Kathedralen, wie sie auch die deutsche Armee im Ersten Weltkrieg vornehmen ließ, deutet etwas an von der willentlichen Zerstörung aller Archive, Bibliotheken, Museen und auch Kathedralen, welche die Futuristen in ihren Manifesten so euphorisch und kriegsblind feierten - und die in veränderter Form, wie wir sahen, noch immer in Stockhausens Feier des Einsturzes des World Trade Centers in New York aufloderte. Doch die zum Teil sehr gegensätzlichen Positionen gegenüber dem Krieg schlagen in dem

6 Chovin, Viktor: Futurismus und Krieg. In: Asholt, Wolfgang / Fähnders, Walter (Hg.): Manifeste und Proklamationen, S. 87. 
bunten Emigrantenhäufchen, das sich in Zürich zusammengefunden hat, dann in Dada unmittelbar um: Eine den Krieg verabscheuende, ihn als menschenverachtendes Massaker charakterisierende und letztlich entschlossen pazifistische Generallinie setzt sich zumindest in diesen Auftaktjahren durch. Man kommt nicht umhin, an die nicht weniger menschenverachtenden Massaker und Folterungen zu denken, welche Alfred Jarrys Ubu Roi an seinen Feinden oder ihm missliebigen Personen verüben ließ.

Auch Dada kämpft gegen das Traditionelle und Ehrwürdige. Aber die Dadaisten tun dies nicht mit dem Ziel einer Führerschaft gleich welcher Art, die damit zu inaugurieren wäre, und auch nicht mit jener Technik-Euphorie, welche den italienischen Futurismus so stark geprägt hatte. Dada ist ganz zweifellos eine avantgardistische Bewegung, welche der anderen, der futuristischen avantgardistischen Bewegung die Luft nehmen möchte, ganz so, wie sich in der Folge oftmals die einzelnen Avantgardisten und avantgardistischen Bewegungen bis aufs Messer bekämpfen sollten und bisweilen mehr untereinander als mit ihren Widersachern in Konflikt gerieten. Gerade der französische Surrealismus sollte aus diesem Blickwinkel nicht nur eine hochgradig kreative, sondern auch eine hochgradig direktive, ja dirigistische Kollektivität darstellen. Diese begann übrigens - wie Maurice Nadeau bereits 1944 darstellte - selbst mit einer Art Gerichtsprozess und Tribunal gegenüber Tzara sowie Dada und musste in der Folge oftmals zum Mittel der Exkommunizierung bestimmter missliebiger Mitglieder greifen. Die avantgardistischen Bewegungen selbst sind Pole der Macht, auch wenn sie sich vor allem als Gegen-Mächte etablieren. Denn in jeglicher akratischer Bewegung ist auch ein enkratischer Kern vorhanden, der bei einer Machtübernahme oftmals alle Strukturen des einstmals Akratischen beherrscht.

Doch lassen wir nun endlich an dieser Stelle Tristan Tzara, die große Führungsfigur des internationalen Dadaismus, jenen Mann, ohne den sich Dada international wohl nie durchgesetzt hätte, zu Wort kommen und stellen zunächst, wie es in unserer Vorlesung guter Brauch ist, einige Biographeme voran!

Tristan Tzara hieß eigentlich Sami oder Samuel Rosenstock und kam am 4. April 1896 im rumänischen Moinestir auf die Welt; er starb in Paris am 25. Dezember 1963. Bevor Tzara 1915 nach Zürich kam, um dort das in Bukarest begonnene Studium der Mathematik und Philosophie fortzusetzen, hatte er vom Symbolismus geprägte Gedichte in rumänischer Sprache verfasst und eine symbolistische Zeitschrift herausgegeben. Aus der Begegnung mit den in die Schweiz geflüchteten Pazifisten Hans Arp, Hugo Ball und Richard Huelsenbeck und dem rumänischen Maler Marcel Janco (den er bereits aus Rumänien kannte) ging die Gründung von Dada Zürich im Cabaret Voltaire hervor. Tzara organisierte die provokatorischen Veranstaltungen im Voltaire, auf deren erster er am 14. Juli 1916 das Manifest des Herrn Antipyrine vortrug, dessen Titel auf seinen im gleichen Jahr 
erschienenen Gedichtband La première aventure céleste de Monsieur Antipyrine anspielt. Im Rahmen der oftmals turbulenten Abende im Voltaire erfand Tzara das dadaistische Simultangedicht.

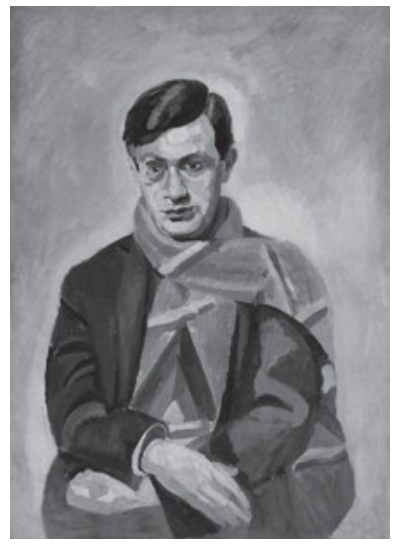

Abb. 47: Tristan Tzara (Moinești, Rumänien, 1896 - Paris, 1963).

Tristan Tzara war auch der Herausgeber der Zeitschrift Dada, in der die künstlerische wie politische Subversion selbst im typographischen Schriftbild durch eine chaotisch anmutende Seitengestaltung zum Ausdruck kam. Ähnlich wirkungsvoll waren seine Vingt-cinq poèmes aus dem Jahre 1918, die seinen Ruf als Dichter begründeten. Er weitete rasch sein Betätigungsfeld räumlich aus und arbeitete zu diesem Zeitpunkt bereits weltweit an nahezu allen Dada-Publikationen mit. So stand er in Paris mit Louis Aragon, André Breton, Paul Eluard, Georges RibemontDessaignes oder Philippe Soupault in Kontakt - und wir hatten ja bereits gesehen, wie Louis Aragon sich als Avantgardist literarisch profiliert hatte. Als er im Januar 1920 nach Paris kam, war seine Ankunft gleichbedeutend mit dem Anfang von Dada Paris. Auch in der französischen Hauptstadt waren die Aktivitäten Tzaras prägend und sorgten dafür, dass die Veranstaltungen der Dadaisten regelmäßig in Happenings ausarteten.

Doch bald schon kam es zu Auseinandersetzungen und Streit. Die Veröffentlichung von André Bretons erstem Manifeste du Surréalisme im Jahr 1924, auf die Tzara mit der Veröffentlichung der Sept manifestes dada noch im selben Jahr antwortete, bedeutete den Anfang vom Ende der dadaistischen Bewegung und zugleich der turbulentesten Phase in Tristan Tzaras Leben. In den dreißiger Jahren engagierte er sich als militanter Schriftsteller, nahm auf Seiten der „Roten“ im Spanischen Bürgerkrieg teil und schloss sich während des Zweiten Weltkriegs der Résistance gegen die Naziherrschaft an. Er engagierte sich auch in der Folge politisch, arbeitete weiterhin als Künstler und Dichter, erlebte aber nicht mehr die großen Höhepunkte seiner Dada-Zeit. Auf der Documenta 81987 in Kassel - und 


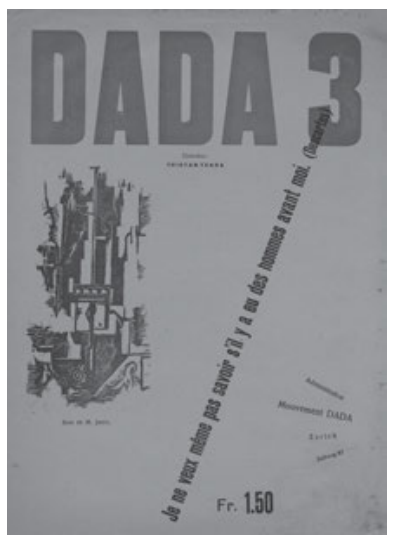

Abb. 48: Cover der Zeitschrift Dada, dritte Ausgabe.

auch hier lässt sich eine Beziehung zu Kassel no invita a la lógica von Enrique Vila-Matas herstellen - wurden Tonaufnahmen Tzaras als offizieller Ausstellungsbeitrag präsentiert. Heute ist die überragende Bedeutung Tristan Tzaras für den Dadaismus unstrittig.

Lassen wir Tristan Tzara uns deshalb erklären, was eigentlich „Dada“ ist! So schrieb er in seinem Manifeste de Monsieur Antipyrine:

DADA ist unsere Intensität: es richtet die Bajonette ohne Konsequenz der Sumatrakopf des deutschen Babys; DADA ist das Leben ohne Pantoffeln und Parallelen; das für und gegen die Einheit ist und entschieden gegen die Zukunft; wir wissen aus Weisheit, dass unsere Gehirne bequeme Kopfkissen werden, dass unser Antidogmatismus genauso ausschließend wie der Beamte ist und dass wir nicht frei sind und Freiheit schreien; strenge Notwendigkeit ohne Disziplin und Moral und spucken auf die Menschheit.

DADA bleibt im europäischen Rahmen der Schwächen, es ist aber trotzdem Scheiße, aber von nun an wollen wir verschiedenfarbig scheißen, um den zoologischen Garten der Kunst mit allen Konsulatsfahnen zu zieren.

Wir sind Zirkusdirektoren und pfeifen mitten in den Winden der Jahrmärkte, mitten in den Klöstern, Prostitutionen, Theatern, Realitäten, Gefühlen, Restaurants, ohi, hoho, bang, bang. ${ }^{7}$

In dieser Passage des am Abend des französischen Nationalfeiertages in Zürich vorgetragenen Manifests zeigt sich Tristan Tzaras Abrechnung mit der Kunst und der eigenen Arbeit, die sozusagen exkrementiert wird. Radikale Selbstkritik und die Zerstörung der eigenen Fundamente nach der Zerstörung der Fundamente des konventionellen Denkens sind Grundbestandteile des dadaistischen Manifestan-

7 Tzara, Tristan: Manifest des Herrn Antipyrine. In: Asholt, Wolfgang / Fähnders, Walter (Hg.): Manifeste und Proklamationen, S. 122. 
tismus im Sinne von Tristan Tzara. Agrammatikalität und Alogik sind zusammen mit allerlei Verstößen gegen die Regeln von Syntax, Grammatik, Logik und Semantik weitere Merkmale, die eine gewichtige Rolle in seinen Texten spielen, da somit die Manifeste des Dadaismus stets auch ihre eigenen Inhalte in die entsprechende Form umzugießen versuchen. Dadaismus ist mehr als ein Aufbegehren: Es ist eine dauerhafte Revolte der Kunst gegen die Kunst, der Menschheit gegen die Menschheit.

Zum Arsenal dadaistischer Verfahren gehören auch Publikumsbeschimpfungen, Provokationen verbaler und nicht-verbaler Art, die Einbeziehung der Zuschauer`innen und Zuhörer^innen - denen Tzara am Ende dieses Manifests etwa seine Liebe erklärt - und viele andere Kennzeichen, die wir schon aus den futuristischen Manifesten kennen. Insbesondere ist es jedoch die Hervorhebung des jeweils kollektiven Charakters des Manifests als Sprachrohr einer Gruppe, welche uns bereits aus dem futuristischen Kontext bekannt ist.

Seit sich im Frühjahr 1916 ein paar Künstler über dem Enzyklopädie-Stichwort „Dada“ einig über die Namensgebung der Bewegung wurden, hatte es Tristan Tzara zusammen mit den beiden Deutschen Hugo Ball und Richard Huelsenbeck - auf den ich gleich noch zurückkommen werde -, aber auch mit Hans Arp und vielen anderen verstanden, eine schlagkräftige Gruppe zusammenzustellen. Diese sollte etwa über ein Jahrfünft ihre große Blütezeit erleben, bis dann 1922 insbesondere unter der scharfen Kritik André Bretons und all jener späteren französischen Surrealisten, die Tristan Tzara vorübergehend für seine Sache begeistern konnte, der Dadaismus an internationaler Ausstrahlungskraft verlor. Rasch schon sollte er unter der großen Zahl sich bildender und wieder verschwindender Ismen immer mehr an eigenem Profil verlieren, bis sich Dada in viele andere künstlerische Bewegungen auflöste.

Von seiner Geburtsstunde an war Dada als in der Schweiz entstandene Bewegung eines rumänischen, auf Französisch schreibenden Dichters im Verein mit deutschen und deutsch-französischen Literaten und Künstlern stark international geprägt und eine einzelne Nationen übergreifende Gruppierung. Eine Tendenz, die sich im weiteren Fortbestehen von Dada noch wesentlich verstärken sollte. Diese Internationalisierung war ohne jede Frage eine der wesentlichen Grundlagen des Versuchs, die Trennung von Leben und Kunst aufzubrechen, wie dies zumindest verbal etwa im letzten oben zitierten Abschnitt intendiert ist. Das Leben sollte mit all seinem Lebenswissen und Überlebenswissen künstlerisch sein, die Kunst wiederum an Lebensprozessen nicht nur beteiligt werden, sondern schlicht das Leben in Kunst, einen Habitus in ein Kunstwerk verwandeln. Zentral ist die von Anfang an in den Raum gestellte Begrifflichkeit der Intensität: Es ist diese Intensität, die als herausragende Kategorie auch die späteren Aktivitäten der dadaistischen Gruppe prägen sollte. Nicht die Länge eines Lebens, sondern 
dessen Intensität zählte! Zweifellos ein Konzept, dessen Modernität nicht zu übersehen war und den Zeitgeist demonstrierte.

Wie ließen sich die spezifisch ästhetischen Konzepte der Dadaisten zusammenfassen, die doch von gewaltigen Unterschieden von Individuum zu Individuum, von Kunstwerk zu Kunstwerk geprägt waren? Es fällt nicht leicht, an dieser Stelle generalisierende Einschätzungen $\mathrm{zu}$ formulieren. ,Die‘ Ästhetik des Dadaismus könnte man nicht nur als Ästhetik der Zerstörung, sondern weit mehr noch als Ästhetik der Enttäuschung verstehen, insbesondere der Enttäuschung des jeweiligen Erwartungshorizontes auf Seiten des Publikums. Ich kann vor diesem Hintergrund der Versuchung nicht widerstehen, Ihnen ein typisches dadaistisches Verfahren vorzuführen, das am 18. Februar 1918 unweit von hier, auf dem Ku'damm in Berlin, von bereits erwähntem Richard Huelsenbeck angewandt wurde. Aber wer ist dieser Herr?

Der deutsche Schriftsteller, Essayist, Chronist und Psychiater Richard Huelsenbeck wurde am 23. April 1892 in Frankenau (Hessen) geboren. Der Sohn eines Apothekers wuchs in Dortmund und Bochum auf, studierte Medizin, Kunstgeschichte und Literatur in München, Paris, Zürich, Berlin und Greifswald. Nach Beendigung seines Studiums arbeitete Huelsenbeck neben anderen Tätigkeiten als Schiffsarzt, wobei ihn seine Reisen nach Asien, Afrika und Amerika führten und es ihm ermöglichten, Essays und journalistische Reiseberichte $\mathrm{zu}$ veröffentlichen. Nach seinem Aufenthalt als Korrespondent der Berliner Illustrierten Zeitung in China und der Mandschurei publizierte er 1930 den Roman China frisst Menschen. 1936 emigrierte Huelsenbeck aus dem zunehmend im Bann der aufstrebenden Nationalsozialisten stehenden Europa in die USA, wo er eine angesehene psychiatrische Praxis führte und die US-amerikanische Staatsbürgerschaft erhielt. Nach Vortragsreisen $\mathrm{zu}$ verschiedenen Themen durch Europa ließ sich Huelsenbeck in seinem letzten Lebensabschnitt 1969 in der Schweiz nieder, wo er auch am 20. April 1974 in Muralto im schweizerischen Tessin verstarb.

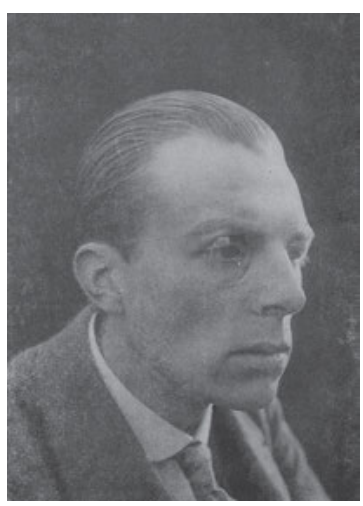

Abb. 49: Richard Huelsenbeck (Frankenau, 1892 - Muralto in der Schweiz, 1974). 
Richard Huelsenbeck schrieb zunächst expressionistische Gedichte, schloss sich jedoch im April 1916 den Züricher Dadaisten um Tristan Tzara an. 1917 verließ er Zürich wieder, ging nach Berlin und proklamierte als „Ur-Dadaist“ unter anderem mit George Grosz und Raoul Hausmann den Dadaismus in Berlin. Er veröffentlichte mehrere Dada-Schriften, die ihn als herausgehobene Figur von Dada Berlin profilierten. Seine scharfe Polemik mit Kurt Schwitters zeigte ihn als engagierten linken Intellektuellen, der sich wiederholt in die Politik seiner Zeit einschaltete. Richard Huelsenbeck war zweifellos einer der ersten Chronisten der Dada-Bewegung, seine Veröffentlichungen zeigen ihn als einen intimen Kenner der Bewegung: So erschien 1964 sein Dada - eine literarische Dokumentation. Auch wenn er später zahlreiche andere Berufe erfolgreich ausübte, ging er doch mit seinen Dada-Aktivitäten in die Geschichte ein: Auch Tonaufnahmen von Huelsenbeck waren auf der erwähnten Documenta 8 in Kassel zu hören.

Nun aber zur Dada-Rede Huelsenbecks in einer Berliner Galerie im Februar 1918 - wir befinden uns also noch im Zeitraum des Ersten Weltkriegs:

\begin{abstract}
Meine Damen und Herren,
ich muß Sie heute enttäuschen, ich hoffe, dass Sie es mir nicht allzu übel nehmen. Aber wenn Sie es mir übel nehmen, ist es mir auch egal. Wir sind hier für eine Dichterlesung zusammengekommen. Sie wollen einige Dichter hören, wie sie sich präsentieren und wie sie ihre Verse vortragen. Die Dichter sind Träger der Kultur und Sie wollen die Kultur absorbieren. Sie haben Geld gezahlt, um die Kultur absorbieren zu können. Aber ich muß Sie, wie gesagt, enttäuschen. Ich habe mich entschlossen, diese Vorlesung dem Dadaismus zu widmen. Der Dadaismus ist etwas, was Sie nicht kennen, aber Sie brauchen ihn auch gar nicht zu kennen. Dadaismus war weder eine Kunstrichtung noch eine Richtung in der Poesie; noch hatte er etwas mit der Kultur zu tun. Er wurde während des Krieges in Zürich im Cabaret Voltaire von Hugo Ball, von mir, von Tristan Tzara, Janco, Hans Arp und Emmy Hennings gegründet. Dada wollte mehr sein als Kultur und es wollte weniger sein, es wußte nicht recht, was es sein wollte. Deswegen, wenn Sie mich fragen, was Dada ist, würde ich sagen, es war nichts und wollte nichts. Ich widme deshalb diesen Vortrag der respektierten Dichter dem Nichts. Bitte bleiben Sie ruhig, man wird Ihnen keine körperlichen Schmerzen bereiten. Das einzige, was Ihnen passieren könnte, ist dies: dass Sie Ihr Geld umsonst ausgegeben haben. In diesem Sinne, meine Damen und Herren. Es lebe die dadaistische Revolution. $^{8}$
\end{abstract}

Deutlicher kann man Konventionen und Erwartungshaltungen ebenso im Bereich des Kultur- wie des Wissenschaftsbetriebs nicht ent-täuschen. Denn Huelsenbeck blieb in seiner kurzen Rede umgänglich und elegant, ohne abrupt und brutal zum

8 Huelsenbeck, Richard: Dadarede, gehalten in der Galerie Neumann, Berlin, Kurfürstendamm, am 18. Februar 1918. In: Asholt, Wolfgang / Fähnders, Walter (Hg.): Manifeste und Proklamationen, S. $139 \mathrm{f}$. 
Publikum zu werden. Zugleich war die Bezeichnung von Dada als „Nichts“ eine Provokation für alle, die eine Bewegung mit Inhalten, Zielen und Absichten verbinden. Sollte es wirklich wahr sein, dass Dada all dies negierte, dass es gar keine Intention gab und schon gar keine künstlerische? Stand Dada einfach für das Nichts, für eine komplette Verweigerung - oder, um mit Enrique Vila-Matas zu sprechen, für eine „Literatur des Nein“?

Diese Regeln von Kunst und deren Vermittlung werden ebenso vorgeführt wie das Geld, das den gesamten Kunstbetrieb, selbst noch in Kriegszeiten, in Gang zu halten pflegt. Wie sehr er von diesem Geld abhängig ist, können Sie sehr anschaulich am Beispiel der Coronavirus-Krise studieren: Ohne die ständige Einspeisung von Geldern sowie verschiedensten privaten und öffentlichen Zuwendungen bräche der gesamte Kunst- und Literaturbetrieb zusammen. Erstaunlich und bemerkenswert ist bei dem späteren Dada-Chronisten Huelsenbeck die frühe Historisierung des Dadaismus, der schon fast wie eine Bewegung der Vergangenheit erscheint. Und doch teilt auch diese Dadarede mit den anderen Manifesten, Manifestationen und Proklamationen immer das Spiel mit dem Unsinn, dem Nonsens, dem ausbrechen aus einer gegebenen Logik, einer gegebenen Wortwahl, die zugleich markiert und transgrediert wird.

Damit wird deutlich, dass hinter Dada - mehr wohl als hinter dem italienischen Futurismus - ein raffiniertes künstlerisch-literarisches Spiel steckt, ja vielleicht mehr noch: das Spiel einer Kunst, die keine Kunst mehr sein will (und eben deshalb Kunst ist). Vielleicht lässt sich gerade auch unter diesem Aspekt jene Ästhetik der Negation erkennen, die begrifflich schon früh wohl von Walter Pabst ${ }^{9}$ ins Feld geführt wurde und in der Tat viele, wenn auch beileibe nicht alle avantgardistischen Bewegungen und Kunsthaltungen prägt. Auch hier zeigt sich, wie Winfried Wehle ${ }^{10}$ einmal formulierte, die Fähigkeit der Avantgarde, Kunst noch aus der Zerstörung der Kunst zu machen und eine „ganz neue Ästhetik“ hervorzubringen. So lässt sich selbst eine Dadarede aus der Historisierung und dem Spiel zwischen Diskurs und Metadiskurs noch in Kunst, in Dada-Kunst, verwandeln.

Zweifellos war der Druck der enormen Beschleunigung künstlerischer Verfahren und Kommunikationsformen, die mit dem Aufkommen der historischen Avantgarden einhergingen, besonders hoch auf die zeitgenössischen Dichtungs-

9 Vgl. Pabst, Walter: Dichtung als Experiment und Spiel. In (ders.): Französische Lyrik des 20. Jahrhunderts. Berlin: Erich Schmidt Verlag 1983, S. 210 ff.

10 Vgl. Warning, Rainer / Wehle, Winfried (Hg.): Lyrik und Malerei der Avantgarde. München: UTB 1982; sowie Wehle, Winfried: Lyrik im Zeitalter der Avantgarde. Die Entstehung einer ganz neuen Ästhetik zu Jahrhundertbeginn. In: Janik, Dieter (Hg.): Die französische Lyrik. Darmstadt: Wissenschaftliche Buchgesellschaft 1987, S. 408-480. 
formen, die im Grunde bereits seit Baudelaires Poèmes en prose in einen erheblichen Wandlungsprozess eingetreten waren. ${ }^{11}$ Das lyrische Ich konnte sich zuvor nur in hochgradig kodierter, versifizierter Sprache darstellen; seit Charles Baudelaire aber lösen sich diese Konventionen mit zunehmender Geschwindigkeit auf. Hugo Friedrich hat in seinem Buch Die Struktur der modernen Lyrik diese Entwicklung nachgezeichnet, sie zugleich aber auch exorzistisch als einen Irrweg gedeutet, der von Baudelaire ausgehend über Verlaine zu Rimbaud und über diesen ins 20. Jahrhundert und zur von Friedrich negativ beurteilten Auflösung lyrischer Formen geführt habe.

Diese literarhistorische Entwicklungslinie ist, unter Einschluss von Stéphane Mallarmé, ganz ohne jeden Zweifel von zentraler Bedeutung. Nicht umsonst hatte im Übergang zur Entstehung der historischen Avantgarden noch ein Marinetti in seinen Rezitationsabenden Lyrik von Baudelaire bis Mallarmé vorgetragen. In dieser sich rasch wandelnden Traditionslinie gründet ein guter Teil der von den Avantgardisten und insbesondere auch den italienischen Futuristen verfolgte ostentative Traditionsbruch. Der unaufhaltsame Hang zum „vers libre“ machte sich etwa bei Verlaine, aber selbstverständlich auch bei vielen anderen Lyrikern des Fin de siècle bemerkbar. Von dort zu den „befreiten Versen“ war es nur noch ein kleiner Schritt. Die Grenze zur rhythmisierten Prosa wurde an dieser Stelle fließend, die Grenzziehungen zwischen den traditionellen Genres waren nicht länger fix.

Der Verslibrismus bildet seit Gustave Kahn, wie etwa Winfried Wehle betonte, eine feste Größe innerhalb der Sprache und den Konventionen der Lyrik. Jede formale Bindung der Sprache, ebenso im Vers wie in der Prosa, wurde nun zunehmend in Frage gestellt und abgeworfen; jede grammatikalische Bindung wurde erschüttert und der Weg freigemacht zu Marinettis Parole in libertà, zu seinen Befreiten Wörtern. Schon um 1912 hatte der Schweizer Blaise Cendrars, ${ }^{12}$ eine der schillerndsten Figuren quer zu den verschiedenen Ismen seiner Epoche, die Abschaffung der Interpunktion durchgeführt. Die Zeilenanordnung hatte spätestens seit den Futuristen keinen Bestand mehr. Das lyrische Ich war ebenfalls längst schon aus dem Zentrum der lyrischen Schreib- und Sprechweise verdrängt. Alles in Kunst und Literatur schien sich mit einer ungeheuren Vehemenz und

11 Vgl. hierzu die erstmals 1956 klassische Studie von Friedrich, Hugo: Struktur der modernen Lyrik. Von der Mitte des neunzehnten bis zur Mitte des zwanzigsten Jahrhunderts. 9. Auflage der erweiterten Neuausgabe. Reinbek bei Hamburg: Rowohlt 1979.

12 Vgl. Chudak, Henrik (Hg.): L'imaginaire poétique de Blaise Cendrars. Warschau: Presses Universitaires 2009; sowie Leroy, Claude: Eros géographe. Lille: Presses du Septentrion 2010; sowie (ders., Hg.): Cendrars à l'établi: 1917-1931. Paris: Editions Non-Lieu 2009. 
Beschleunigung zu verändern. Spätestens mit dem Beginn des Ersten Weltkriegs war zwar die dritte Phase beschleunigter Globalisierung vorüber und Geschichte; doch die relative Autonomie von Literatur und Kunst garantierte noch immer eine rasante Beschleunigung, die mit den politischen Veränderungen in Europa einherging. Die Speerspitze dieser radikalen Veränderungen bildeten die historischen Avantgarden - und die militärische Metaphorik hätte vielen der Avantgardisten gefallen.

Denken Sie in diesem Zusammenhang zurück an die futuristischen Manifeste, die wir in unserer Vorlesung analysiert haben, und an die Verdrängung des Ich! Man könnte mit Blick auf das literarische Teil-Feld und die Veränderungen der literarischen Verfahren sehr wohl davon sprechen, dass Lyrik durch die Avantgarden in eine produktive Vielstimmigkeit geführt wurde. Um 1912 schien auch hier das Machbare vielleicht noch nicht getan, aber zumindest doch schon entworfen: Gerade eine Figur wie Blaise Cendrars lotete in seinen Gedichten, Prosaschriften und Erzähltexten die Machbarkeit möglicher Veränderungen immer wieder aus. ${ }^{13}$ Diese Behauptung wäre freilich zu relativieren, nicht zuletzt von einer die außereuropäischen Literaturen - etwa der Romania - einbeziehenden Position aus. Doch dies wollen wir im sich anschließenden Kapitel, das sich mit den Literaturen in Lateinamerika beschäftigen wird, angehen. ${ }^{14}$ Halten wir jedoch fest: Simultaneität und Ubiquität sind innerhalb dieser Entwicklungen im Übrigen auch in der Lyrik wichtige Theoreme und Bedingungen künstlerischer Reflexion! Sie sind dies umso mehr, als die kurze lyrische Form es ja erlaubt, der Leserschaft beziehungsweise den Zuhörerinnen und Zuhörern einen quasi-simultanen Zugang zur neuen, innovativen Wortkunst zu gewähren.

Genau als Wortkunst aber, als Sprachkunst also, musste auch die Lyrik wie wir bereits sahen - auf jenes Vehikel, jene Konvention zurückgreifen, mit Hilfe derer wir den Alltag bewältigen und mit Hilfe derer die europäischen Großmächte ihren eigenen Untergang im Ersten Weltkrieg betrieben. Inwieweit sich die dadaistische Kunst ihrerseits im Kontext der historischen und sozialen Entwicklungen und Probleme ihrer Zeit sah, mag aus jenem Manifest von Tristan Tzara hervorgehen, das ich Ihnen in der Folge gerne vorführe. Auch dieser Text wurde auf einer Dada-Soirée in Berlin, am 12. April 1918, vorgetragen und kam als Faltblatt ebenfalls in dieser Stadt heraus. Richard Huelsenbeck ließ es 1920 im Auftrag der Dada-Bewegung abdrucken und versah es mit dem Hinweis, dass es sich hierbei um das erste Dada-Manifest in deutscher Sprache handele und

13 Vgl. hierzu das Kapitel „Simulationen“ in Ette, Ottmar: ZwischenWeltenSchreiben. Literaturen ohne festen Wohnsitz (ÜberLebenswissen II). Berlin: Kulturverlag Kadmos 2005, S. 61-101.

14 Vgl. Landa Goyogana, Josu: Ensayos. México: La Saeta del Centauro 2013. 
dass es von Richard Huelsenbeck verfasst worden sei. In diesem Zitat wird zum einen der internationalistische Charakter der Bewegung, zum anderen aber auch die mit der Verbindung von Kunst und Leben einhergehende gesellschafts- und kunstkritische Stoßrichtung unmissverständlich klar. Unter der durcheinander wirbelnden Typographie der Überschrift „Dadaistisches Manifest“ lesen wir:

Die Kunst ist in ihrer Ausführung und Richtung von der Zeit abhängig, in der sie lebt, und die Künstler sind Kreaturen ihrer Epoche. Die höchste Kunst wird diejenige sein, die in ihren Bewußtseinsinhalten die tausendfachen Probleme der Zeit präsentiert, der man anmerkt, dass sie sich von den Explosionen der letzten Woche werfen ließ, die ihre Glieder immer wieder unter dem Stoß des letzten Tages zusammensucht. Die besten und unerhörtesten Künstler werden diejenigen sein, die stündlich die Fetzen ihres Leibes aus dem Wirrsal der Lebenskatarakte zusammenreißen, verbissen in den Intellekt der Zeit, blutend an Händen und Herzen.

Hat der Expressionismus unsere Erwartungen auf eine solche Kunst erfüllt, die eine Ballotage unserer vitalsten Angelegenheiten ist?

\section{Nein! Nein! Nein!}

Haben die Expressionisten unsere Erwartungen auf eine Kunst erfüllt, die uns die Essenz des Lebens ins Fleisch brennt?

\section{Nein! Nein! Nein! ${ }^{15}$}

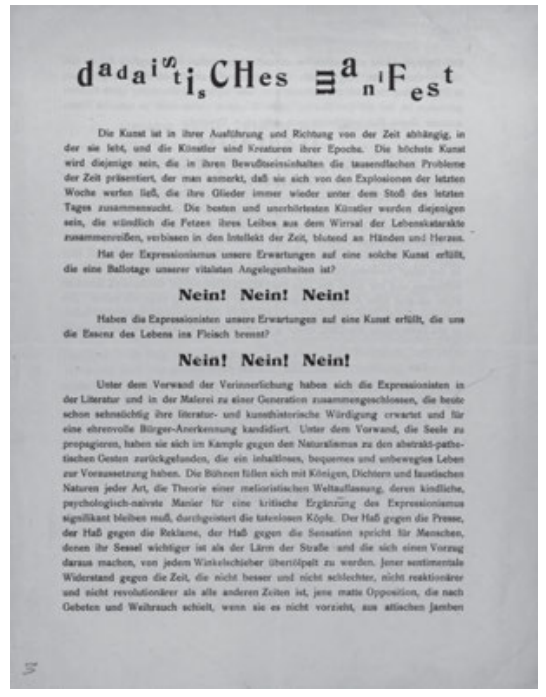

Abb. 50: Tristan Tzara, Franz Jung, George Grosz, u. a.: Dadaistisches Manifest, 1920.

15 Tzara, Tristan / Jung, Franz / Grosz, George u. a.: Dadaistisches Manifest (Faksimile). In: Asholt, Wolfgang / Fähnders, Walter (Hg.): Manifeste und Proklamationen, S. 145. 
Was zunächst wie eine Abrechnung mit dem Expressionismus aussieht, ist wesentlich mehr: eine Abrechnung mit der Kunst und ihrer Gesellschaft! Der Intellektuelle Duktus unterscheidet sich von Beginn an von den Manifesten, die wir bislang zur Kenntnis genommen haben. Die Berliner Dadaisten rund um Huelsenbeck erzählen uns zu Beginn ihres Manifests auch keine Geschichte, fahren mit ihrem Rennwagen nicht in den Straßengraben, überfliegen keine Fabrikschlote, fordern keinen Krieg. Vielmehr reagieren sie auf die grauenhaften Zerstörungen, welche der Erste Weltkrieg mit sich gebracht hat - und all die politischen Versuche von Revolutionen oder eines Neuanfangs, welche in Deutschland die Geburtswehen der Weimarer Republik begleiten sollten. Dada Berlin schreibt sich ein in eine revolutionäre Situation, in welcher klar ist, dass das Alte zu Ende geht, aber unklar bleibt, wie das Neue sich gestalten wird.

Entscheidend ist bereits zu Beginn dieses Manifests, dass dem Bisherigen nicht nur ein klares Nein entgegengeschleudert wird, sondern dass dem Leben - die Rekurrenz dieses Lexems im Manifest ist bemerkenswert - eine Orientierungsfunktion zukommt. Kunst und Leben müssen eins sein! Denn diesem Leben müsse die Kunst - ebenso auf einer individuellen wie auf einer kollektiven Ebene - gewachsen sein und die Erwartungen einer in Aufruhr befindlichen Gesellschaft erfüllen. Dabei macht der Dadaismus aus der Ablehnung des Dadaismus eine Kunst. So lautet der letzte Satz: „Gegen dies Manifest sein, heißt Dadaist sein!“16

Im Verlauf dieses Dadaistischen Manifests, aber auch im weiteren Verlauf der Dada-Bewegung versuchte man an den verschiedensten Orten, sich von all dem zu trennen, mit all dem zu brechen, was für die negativen Entwicklungen der vergangenen Jahre und Jahrzehnte verantwortlich gemacht werden konnte. Das revolutionäre Potential des Dadaismus ist nicht ,nur` künstlerischer, sondern auch eminent politischer Natur: und eben dies ist gerade bei Dada Berlin der Fall.

Bereits der Beginn des Manifests vermittelt einen klaren Eindruck: Der Dadaismus beschritt rational eine Abkehr vom Rationalen, versuchte den Sündenfall des Menschen durch eine Zerstörung dieser Logik, die in den Abgrund geführt hatte, zu überwinden. Anakoluthe, Katachresen und Paradoxa standen daher bei den Dadaisten hoch im Kurs: Es ging um die rational fundierte Einbeziehung des Irrationalen. Den Weg in diese rational begründete Aufwertung des Irrationalen, des Instinkts und seiner Darstellung hatte bereits Alfred Jarry mit dem Konzept seiner „Pataphysik“ gewiesen. Aus dieser Tendenz erklärt sich auch der Versuch der Dadaisten und anderer avantgardistischer Bewegungen,

16 Tzara, Tristan et al: Dadaistisches Manifest. In: Asholt, Wolfgang / Fähnders, Walter (Hg.): Manifeste und Proklamationen, S. 147. 
die Sprache von jeder vorherigen Bedeutung abzuziehen und damit abstrakt zu machen: Die Sprache bot den Zugang zu (fast) Allem und damit den ersehnten Hebel zu grundlegender Veränderung von Kunst, Politik, Gesellschaft und Leben.

Auch dies lässt sich als eine Art Befreiung der Worte verstehen: und zwar gerade von jenen Bedeutungen, jener Semantik, welche die bürgerliche Gesellschaft eben diesen Wörtern gab, wodurch sie sie fixierte. Die Dinge aber sollten wieder in Bewegung gesetzt werden, auch und zuallererst auf Ebene der Sprache. In der Bildenden Kunst verliefen diese Entwicklungen im Übrigen weithin analog. Überhaupt gilt es $\mathrm{zu}$ betonen, dass sich in kaum einer anderen kunst- und literarhistorischen Epoche in so tiefgreifender Weise von einer „wechselseitigen Erhellung der Künste“, wie man mit Oskar Walzels Formulierung aus dem Jahre $1917^{17}$ sagen könnte - oder von einer zutiefst inter- und transmedialen Verzweigtheit der avantgardistischen Kunstformen sprechen lässt. Das „mouvement perpétuel“, um mit Louis Aragon zu sprechen, also die ständige Bewegung, der alle Kunst und alle Wirklichkeitserfassung unterworfen wird, ${ }^{18}$ sollte im Übrigen auch ganz wesentlich den Rezipienten, den Kunstrezipienten erfassen, der gleichsam zwanghaft zum Kunstproduzenten, zum Kunstschaffenden werden solle.

Avantgardistische Kunst ist - wie schon mehrfach betont - eine Kunst, welche die Grenze zum Publikum, zur Zuhörerschaft oder den Zuschauerinnen und Zuschauern, niederreißen möchte. Der Dadaismus ist hierbei die vielleicht radikalste Form einer solchen Kunstauffassung, stellt sie doch die Grenze zwischen den Produzenten und den Rezipienten von Kunst wie auch die Institution Kunst selbst in Frage. Bei den Dadaisten lässt sich im Allgemeinen deutlich eine klare Verabsolutierung des Spielcharakters von Kunst nachweisen, der wiederum die Kunst mit dem Leben verbindet. Nicht von ungefähr sollte dann auch das Spiel eine wichtige Rolle bei André Breton, der ja durch die ,Schule‘ des Dadaismus gegangen war, in seinem erstem Surrealistischen Manifest spielen. Der dadaistische Künstler ist ein Spieler, der testet und ausprobiert, was geht. Inwieweit sich hier eine Beziehung zu den Ästhetiken der Postmoderne herstellen lässt, wird freilich zu einem späteren Zeitpunkt in unserer Vorlesung zu erörtern sein.

Mit dem Spielcharakter, der Aufwertung des Zufälligen und Aleatorischen sowie der Stärkung des Irrationalen und Unbewussten verbindet sich zunehmend eine Poetik, die auf die surrealistische „écriture automatique“ hinauslaufen und im Rahmen surrealistischer Kunst- und Literaturproduktion im Mittelpunkt

17 Vgl. Walzel, Oskar: Wechselseitige Erhellung der Künste (1917). In (ders.): Gehalt und Gestalt im Kunstwerk des Dichters. Berlin: Athenaion-Verlag 1923, S. 265-281.

18 Vgl. Millares, Selena (Hg.): Diálogo de las artes en las vanguardias hispánicas. Madrid - Frankfurt am Main: Iberoamericana - Vervuert 2017. 
stehen wird. Überhaupt lässt sich beobachten, dass die verschiedensten historischen Avantgarden, unabhängig von ihrer jeweiligen politischen Ausrichtung, bestimmte Verfahren und Methoden teilen und entsprechend weiterentwickeln.

Tristan Tzara hat die neuartige Selbstdefinition des Dichters als jener Instanz, die im Gedicht selbst die Zerstörung des traditionellen Gedichts ankündigt und die Leserschaft mobilisiert, nicht nur verbal angekündigt, sondern auch schon zum Teil verwirklicht und eingelöst. Tzaras Verfahren war dabei sehr einfach: Es ist eine Technik, die Sie alle zuhause einmal ausprobieren könnten. Das Rezept, Wie man ein dadaistisches Gedicht fabriziert, findet sich im folgenden Zitat:

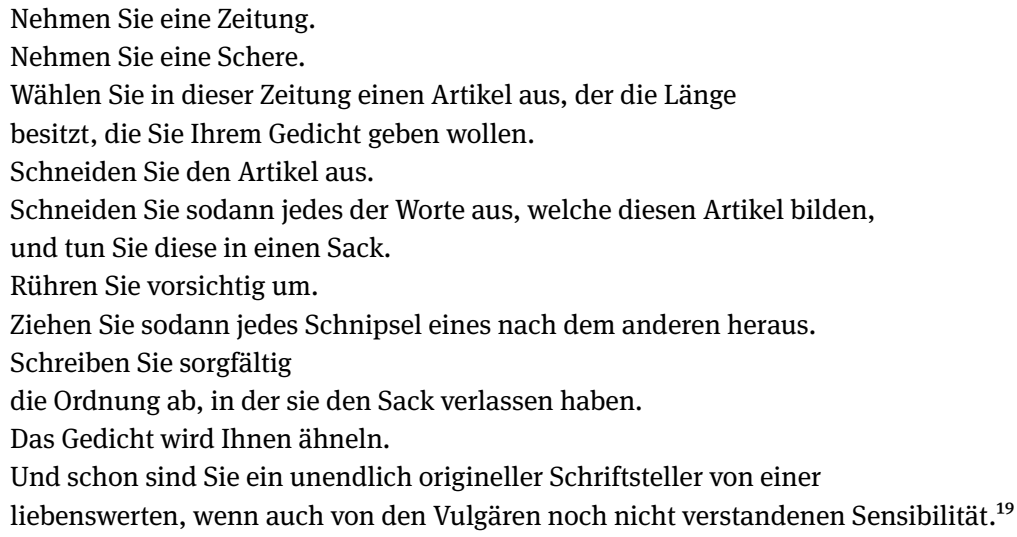

Tristan Tzara hat mit diesen Sätzen eine Anleitung zur Fabrikation eines Gedichts für Jedermann verfasst, was zugleich bedeutet, dass jede Zeitungsleserin und jeder Zeitungsleser im Handumdrehen zu einem Dichter, einer Dichterin werden kann. Die Lyrik ist folglich nicht länger von einer Aura des Quasi-Sakralen umhüllt, ist nicht länger die Sache weniger Eingeweihter, die allein der Lyrik teilhaftig sind. Dieses Gedicht ist zum einen eine im Duktus der Anleitung, des Rezepts daherkommende Form einer literarischen Aktivierung des Publikums, das aus seiner passiven Leserrolle herausgerissen werden und selbst zur Produktion von Gedichten, genauer: von dadaistischen Gedichten, angeregt werden soll. Wir haben es folglich mit einem Akt der Demokratisierung von Literatur zu tun.

Tzaras Gedicht ist zum zweiten eine gewisse Antwort darauf, dass sich jede Literatur immer auf andere Texte bezieht, dass die Intertextualität also stets eine zentrale Dimension des Kunstwerks ist. Denn Intertextualität, die Bezüglich-

19 Tzara, Tristan: Pour faire un poème dadaïste (1918). In Béhar Henri (Hg.): Tristan Tzara. Euvres complètes. 6 Bde. Paris : Flammarion 1975, Bd. I, S. 382. 
keit eines Textes auf Texte anderer Autorinnen und Autoren, ist in der Tat das pochende Herz von Literatur überhaupt. Diese Einsicht macht uns Tzara in seiner Anleitung sehr bewusst.

Zum dritten ist der Bezugstext im Falle dieses Gedichtes eine Zeitung, die Tageszeitung, welche von ihrer Definition her eine Mimesis, eine Darstellung der Wirklichkeit, bildet und abbildet, so dass sich unser Gedicht hierauf aufbauend durchaus noch als sekundäre, abgeleitete Repräsentation von Mimesis begreifen lässt. Es wird folglich keine eigene oder gar ,heilige“ Sphäre des Gedichts aufgebaut, sondern vielmehr das Alltägliche aufgegriffen und in einer klar definierten Produktion in ein Gedicht transformiert.

Viertens ist diese Dimension mimetischer Kunstauffassung aber in den Modus der Ironie und wohl mehr noch Parodie überführt, so dass sich die Tätigkeit des Dichters hinsichtlich der Darstellung von Wirklichkeit auf die mechanische und materielle Tätigkeit des Zerschneidens kapriziert und beschränkt. Mit dieser Aktivität ist eine Arbeit an der Sprache mitbedeutet, welche letztere gleichsam in ihre Einzelteile zerlegt und so ebenso die syntaktische wie grammatikalische, die semantische wie logische Verbundenheit auflöst und ein Werk hervorbringt, das aus einer vorhandenen Sprache ohne Neologismen geschaffen ist, aber zugleich diese vorhandene Sprache der bürgerlichen Gesellschaft atomisiert. Es ist, als ob die vorhandenen Sprachstrukturen gleichsam implodierten. Man könnte an dieser Stelle sehr wohl von einer Destruktion sprechen, die wieder in eine Konstruktion übergeht und damit eine Dekonstruktion vor Augen führt, mit der wir uns im Zusammenhang mit den Ästhetiken der Postmoderne noch beschäftigen müssen. Auch aus dieser Perspektive kommt der Parodie eine sehr wichtige textuelle Funktion zu.

Wir müssen fünftens aber zu bedenken geben, dass die Tätigkeit der Schere, welche ansonsten im öffentlichen Bewusstsein eher mit der Zensur gekoppelt wäre, die Grenzen des Wortes erstaunlicherweise sehr wohl respektiert. Die Tätigkeit des dadaistischen Wortkünstlers oder Dichters greift mithin nicht dahinter zurück: Die zerschneidende Tätigkeit löst nicht die Wortgrenzen auf, indem sie etwa nur noch die einzelnen Buchstaben autonom gelten ließe, sondern produziert nach wie vor Worte, welche freilich aus ihrem Zusammenhang gerissen wurden. Wir haben es in diesem Gedicht über die Verfertigung eines Gedichts durchaus mit einer Ästhetik zu tun, die sich in Verbindung mit Marinettis „Parolibrismus“ bringen ließe, die folglich die Worte aus ihrer syntaktischen wie semantischen Umklammerung ,befreit“.

Zum sechsten erfasst die Parodie den Status des Schriftstellers selbst, der sozusagen in seiner (simplen) Produktivität zum einen bloßgestellt wird, zum anderen in seiner gesellschaftlichen Funktion als jener Agent, der das Gedicht wie das Kunstwerk überhaupt in etwas ihm Ähnelndes überführt, vorgeführt wird. 
Auch hiermit ist, wie schon oben bemerkt, eine gewisse Demokratisierung von Literatur und Kunst verbunden: Der Schriftsteller erscheint nicht mehr als rätselhafter und unnahbarer „grand écrivain“, sondern als ein Alltagsgenosse wie ich und $\mathrm{Du}$. In den Gedichten dieses Schriftstellers gibt es nichts Esoterisches, nichts Unnahbares, nichts Sakrales, sondern lediglich Verfahren, die so einfach sind wie Kochrezepte: „les recettes faciles“ für den Hausgebrauch. Das Gedicht, so heißt es hier, ähnelt Ihnen, ähnelt also diesem Allerwelts-Subjekt. Mag sein, dass es darum auch ein Allerwelts-Gedicht ist.

Siebtens - und vorerst letztens - wird die Parodie der Gedichtherstellung auch noch mit dem Pathos des Unverstandenen ausgestattet, damit zugleich also in eine avantgardistische, noch unbegriffene Vorreiterrolle befördert, womit diese Position der Avantgarde aber zugleich subvertiert wird. Das Unverstandensein von der Menge, der Masse, vom „vulgo“, wird als Sprachgeste zugleich gezeigt und unterspült, wird damit vor allem der Lächerlichkeit preisgegeben. So erfüllt diese einfache Anleitung, „Um ein dadaistisches Gedicht zu machen“, schließlich auch die Funktion, dieses dadaistische Poem seinerseits wieder zu hinterfragen, Das Gedicht kommt semantisch nicht zur Ruhe. Es überschreitet die Grenze zwischen Produktion und Rezeption, zwischen Kunst und Leben, zwischen der Poetik und der Legetik gerade in jenem Punkt, in dem es sich zumindest vom Titel her und auch bezüglich seiner Verfasstheit fast zurückgezogen hätte. Es erlaubt aber gerade nicht die Stabilität, die statische Erstarrung als Kunstwerk.

Denn es handelt sich deutlich um ein dadaistisches Gedicht, das die Provokation der Grenzen zwischen dem scheinbar so leicht zu Trennenden und die Überwindung dieser Grenzen der Leserschaft vor Augen führt. Doch auch hier gilt: Probieren geht über Studieren ... Bewaffnen Sie sich also mit einer Schere und versuchen Sie, einmal die Berichterstattung über - sagen wir - den Coronavirus in ein dadaistisches Poem zu verwandeln! Falls diese Berichterstattung nicht ihrerseits längst wieder ebenso aufgeregte wie weiter aufregende Züge einer Action Art aufweist.

Vergessen wir aber über all diesen Aspekten nicht die „découpage“ und damit die Montage-Ästhetik eines solchen Gedichts, dessen Verfertigung uns hier anempfohlen wird! Denn dieses graphische Element führt uns just zur Ästhetik der Collage, des absichtsvoll Heterogenen, das in einen gemeinsamen Rahmen gestellt wird. Es handelt sich um eine Ästhetik der Montage, welche sich im Übrigen schon aus den veränderten Wahrnehmungsgewohnheiten ergibt, mit denen wir uns bereits beschäftigt haben. Denken Sie dabei an die Buchstaben und Wortfragmente der Kubisten, die gerade diese graphische Dimension der Schrift ins Bewusstsein gehoben haben, wie auch schon die Futuristen und nach ihnen die Dadaisten unterschiedliche graphische Umsetzungen von Wörtern mit verschiedenartigen Schriftarten, Schriftgrößen und Farben kombinierten! In diesen 
graphischen Gestaltungen ist bereits eine Vorform der surrealistischen „Papiers collés“ zu erkennen.

Ein vorrangiges Ziel war es bei diesem Verfahren, zum einen das Rationale gerade durch eine sehr rational bestimmte Vorgehensweise auszuklammern. Zum zweiten war intendiert, die Subjektivität aus dem Gedicht selbst herauszukatapultieren, um das Gedicht nicht mehr länger mit dem Ich verschmolzen zu sehen. Darüber hinaus wird das Gedicht dadurch vielstimmig und polyphon, ganz im Sinne eines Michail Bachtin. ${ }^{20}$ Schließlich ergibt sich aus alledem eine grundlegende Herausarbeitung der graphischen Dimension von Lyrik, wie sie zuvor in Frankreich etwa von Apollinaire in seinen berühmten Calligrammes - auf die wir an späterer Stelle noch zurückkommen werden - vorgeführt worden war. In jedem Falle wird die Wahrnehmung der Materialität des Kunstwerks, die Wahrnehmung seines Artefakt-Charakters, auf allen Ebenen gestärkt und gesteigert.

Dabei ist das Visuelle nur die eine Seite dieser Bewusstmachung: Das Akustische ist eine keineswegs von den Avantgardisten und vor allem den Dadaisten geringer eingeschätzte künstlerische Dimension. Ja, man könnte sagen, dass gerade die Dadaisten es waren, die den Hörsinn für ihr Verständnis von Kunst und Literatur zu nutzen wussten. Die sinnliche Erfahrung sowie die Aktivierung und Mobilisierung des Publikums bilden stets Grundpfeiler dieser avantgardistischen Ästhetik, für die eine phonotextuelle Relationalität, mithin die Beziehung zwischen Text und Klang, eine wichtige Bedeutung besitzt.

Das künstlerische und literarische Interesse gerade der Dadaisten an der akustischen Dimension von Sprache war enorm. Dies erklärt sich zusätzlich zu den bereits genannten Gründen mit dem Hinweis auf die Performativität der dadaistischen Verfahren, Vorführungen und Artefakte. Wir können vom Dadaismus ausgehend eine sehr kreative Weiterentwicklung des Lautgedichts verfolgen, wobei den französischen Autoren im Umfeld der Avantgarde durch das weite Auseinanderklaffen von Schrift und Stimme, Orthographie und Phonetik, im Französischen eine Vielzahl von Möglichkeiten offenstand, diese Differenz zwischen Stimme und Schrift auch visuell vor Augen zu führen.

Besonders eindrucksvoll aber scheint mir eine Performance der frühen Dadaisten in Zürich an einem der frühen ,,soirées“ in der Schweiz, die am 31. März 1916, also mitten im Krieg, stattfand. Dabei ging es im wahrsten Sinne um eine Inszenierung und mehr noch Aufführung, wobei die Druckfassung im Grunde nur eine Art Partitur (oder sogar nur eine Vorstufe dafür) bildete. Das dadaistische Gedicht war für drei Stimmen ausgelegt, die eine als Gesang, die zweite als

20 Vgl. hierzu Bachtin, Michail M.: Die Ästhetik des Wortes. Herausgegeben von Rainer Grübel. Frankfurt am Main: Suhrkamp 1979. 
Rezitativ, unterbrochen von einem rhythmischen Intermezzo. Die Gesangsstimme übernahm Marcel Janco, die beiden anderen Stimmen übernahmen in der Form des Rezitativs dann Huelsenbeck und Tzara selbst. So wurde auf subversive Weise eine dreistimmige Kantate ausgeführt.

Das Entscheidende aber nun war, dass diese drei Stimmen drei verschiedene Texte in drei verschiedenen Sprachen intonierten. Sie finden leicht im Internet eine Aufnahme dieser historischen Aufführung; auch finden Sie dort eine Darstellung der Partitur dieser Performance, die unter dem Titel L'amiral cherche une maison à louer in die Theatergeschichte ebenso eingegangen ist wie in die Literaturgeschichte. Hören und schauen wir uns also beides einmal an, es lohnt sich außerordentlich!

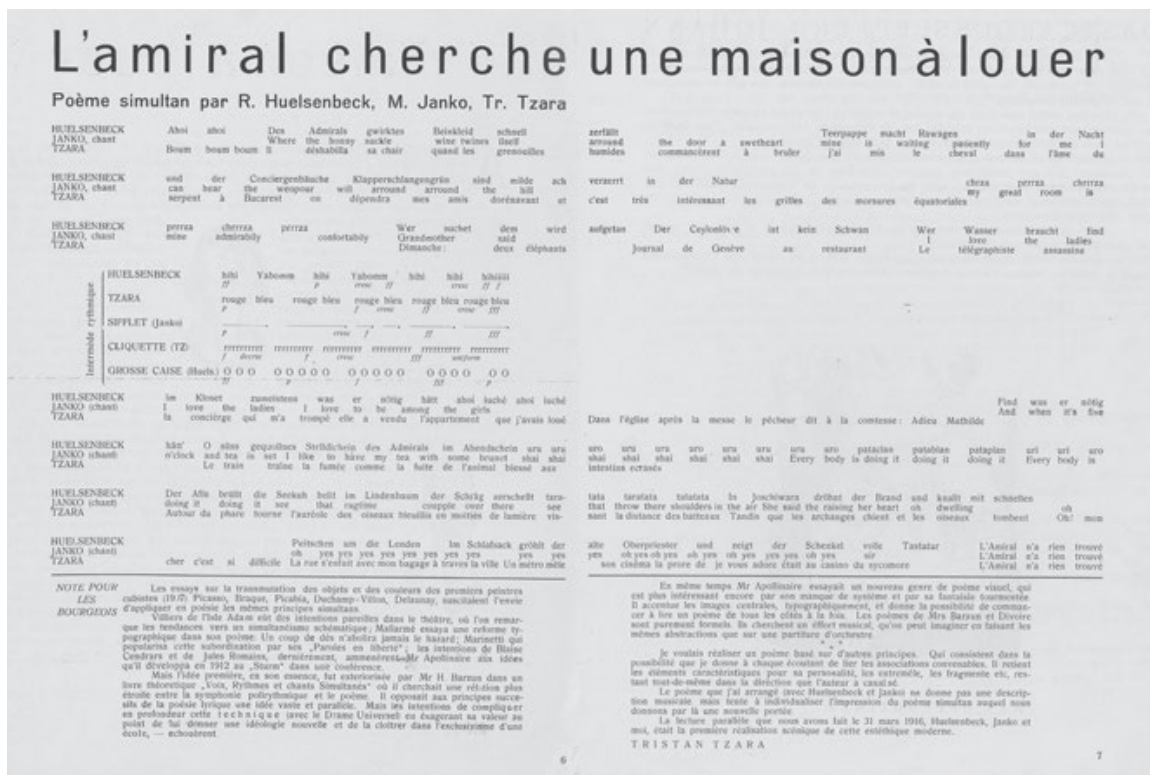

Abb. 51: Marcel Janco, Richard Huelsenbeck, Tristan Tzara: L'amiral cherche une maison à louer, dreistimmiges Simultangedicht. ${ }^{21}$

In einer kurzen Anmerkung für Bourgeois hat Tristan Tzara in dieser schriftlichen, mit abgedruckten Fassung auf die verschiedenen Traditionslinien und den Neuansatz des vielsprachigen Simultangedichts zugleich aufmerksam gemacht.

21 Tonaufnahme online noch abrufbar unter https://www.youtube.com/watch?v=Zrxa6Q3V_rQ (lezter Zugriff 07.06.2020). 
Tzara war also nicht wie Marinetti daran gelegen, eine - im Übrigen nicht haltbare - These von der absoluten, radikalen Neuheit der eigenen Versuche aufzustellen, sondern fokussierte die Aufmerksamkeit seines Lesepublikums auch auf die intertextuelle Verfasstheit allen Schreibens. So verwies die gewiss zentrale Figur des Dadaismus auf den wichtigen Anstoß durch die zeitgenössische Malerei ab 1907: insbesondere durch den Kubismus und die Maler und Künstler Picasso, Picabia, Delaunay, Duchamp und viele mehr. Einmal mehr wird die intensive Beziehung zwischen den verschiedenen Künsten, folglich die „wechselseitige Erhellung der Künste“ gemäß Oskar Walzel, thematisiert. In der Lyrik wird Stéphane Mallarmés Gedicht Un coup de dés, das im 20. Jahrhundert fast zum berühmtesten Gedicht aus jener Zeit mit Kultstatus bei den neo-avantgardistischen Theoretikern avancierte, erwähnt. Ebenso wie die Versuche Guillaume Apollinaires, mit Frühformen des Bildgedichtes zu experimentieren; Frühformen, mit denen wir uns, wie bereits betont, noch an späterer Stelle in unserer Vorlesung auseinandersetzen wollen.

L'amiral cherche une maison à louer, das simultane Gedicht, wie es schon in der Überschrift bezeichnet wird, erscheint in Form einer Partitur und macht zugleich auf die Simultaneität der aufführenden Instanzen, also des Gesangs und der Rezitation, und die Simultaneität der Rezeption aufmerksam, also die Notwendigkeit der Zuhörerschaft, sich auf die drei Sprachen, drei Stimmen, drei Texte simultan einzulassen. Dies ist natürlich eine gezielte Überforderung der anwesenden Rezipient ${ }^{\star}$ innen. Es impliziert eine Überbelastung der Codes hin zum Nonsens: Das Gedicht spielt mit dem Abbrechen und dem Abgrund der Kommunikation, ohne auch nur ansatzweise Un-Sinn darzubieten. Denn die gegen alle Kriege und alle Krieger gerichtete Intention der Dadaisten stand außer Frage.

Dabei scheint sich das Gedicht durch seine vieldeutige und viellogische Simultaneität gleichsam selbst wieder aufzuheben. Im rhythmischen Intermezzo dringt der Klang offensichtlich an die Stelle der Semantik, löst das gerade noch Übriggebliebene der Bedeutung in die Rhythmisierung auf, die von der Zuhörerschaft aufgenommen werden kann. Die Worte selbst werden in diesem Intermezzo $\mathrm{zu}$ rhythmisch wiederholten Elementen und doch ist die semantische Dimension nicht völlig verschwunden: Huelsenbecks „Hihihi“ steht in einem eigenartigen Kontrast zu Tzaras wiederholtem „rouge bien rouge“. Jenem Rot, das in Kriegszeiten wohl weniger auf die Fahne der Kommunisten und der herannahenden Revolution, als vielmehr auf das auf den Schlachtfeldern vergossene Blut aufmerksam macht.

Denn nicht umsonst haben wir es bei diesem Admiral mit einen der Anführer offensiver Kriegshandlungen $\mathrm{zu}$ tun, eine Tatsache, die freilich schon in des Admirals Wunsch, ein Haus zu mieten, und in der schlussendlichen Verneinung dieses Wunsches - der Admiral fand eben nichts - zum Ausdruck kommt. Es ist 
immerhin ein Admiral, der im Simultangedicht mit einem süßen Stelldichein im Abendschein in Verbindung gebracht wird, folglich mit einem intimen romantischen Abenteuer, das in den Jahren des Ersten Weltkrieges als hochgradig unmoralisch erscheinen muss: angesichts der Ströme von Blut, die überall - von Trommeln Tzaras untermalt - vergossen werden. Die Kriegsgeräusche im Gedicht sind unüberhörbar.

Umso schadenfroher klingt da die von allen drei Stimmen dann in derselben Sprache simultan vorgetragene Abschlusssequenz: „L’Amiral n’a rien trouvé.“ Der Admiral hat also kein Haus, kein ,pied-à-terre“, für seine Wünsche gefunden: Wie sollte er auch, da er doch als ,fliegender Holländer' für die Kriegsaktivitäten nicht an Land, sondern auf hoher See zuständig ist. Er findet zugleich aber auch kein Asyl, keinen Unterschlupf, wie die Kriegsgegner und Pazifisten in der Schweiz. So ist dieses Gedicht in dadaistischer Manier nicht einfach nur ein sinnloser Ulk, ein aufwendig inszenierter Un-Sinn, sondern ein veritables Anti-Kriegsgedicht, das zugleich die Grenzen des Sagbaren, des Verstehbaren, der literarischen Kommunikation erprobt.

Ist die Avantgarde insgesamt ein Grenzphänomen, so ist dieses Gedicht auch und vor allem durch seine Simultaneität eine Grenzerfarung für jedes Publikum, auch das zeitgenössische Publikum im Cabaret Voltaire. Nicht umsonst sprach Hugo Ball vom Untergang der menschlichen Stimme im Lärm: Rund um die Schweiz tobte der Kriegslärm. Wie nahe waren da die Assoziationen zum Untergang des Menschen im Lärm und Geschrei des Krieges und seiner zahllosen Opfer! Das Gedicht gibt in seiner Aufführung diese kakophone Lautstärke an die Zuhörerschaft weiter. Der Lärm ist ein Krieg der Stimmen, in welchem das Französische, das Englische und das Deutsche die Stimmen der miteinander im Krieg befindlichen Vaterländer repräsentieren.

Gegen diese interlinguale kriegerische Auseinandersetzung der Vaterländer wurde ganz bewusst der Internationalismus oder auch Kosmopolitismus der Kunst und der Gründungs-Dadaisten in Zürich gesetzt. Dass all dies als eine Posse auf höchste staatliche Autorität in Kriegszeiten vom Boden der neutralen Schweiz aus gedeutet werden musste, ist sonnenklar. Die Mehrsprachigkeit des Lautgedichts ist daher programmatischer Natur: Sie zeigt durch den bewussten Nonsens den Un-Sinn dieses ganzen Krieges sprachlich eindrucksvoll auf.

Ist die Lyrik der damaligen Zeit verstehbar? Wie kann literarische Kommunikation verlaufen, wie kann sie hergestellt werden und wie kann sie wieder verloren gehen? Wie ist die Vielsprachigkeit und Vielstimmigkeit in ein Gedicht integrierbar und vor allem: Ist es dann auch noch aufführbar? Was bedeutet das Theorem der Simultaneität, wenn wir es - ähnlich wie im Marinetti'schen Bombenhagel - in einem hochkontrollierten Stimmenhagel aufgehen lassen? Wo liegen die Grenzen der Verstehbarkeit und wie können wir Kunst auf diesen 
Grenzen machen? Diese und viele andere Fragen beantwortet das Gedicht auf seine eigene Weise. Es ist vor allem aber dies: künstlerisch vieldeutiger Ausfluss einer theoretischen Beschäftigung in der praktischen Umsetzung ausgeklügelter Performanz.

Die Grenzen konventioneller Kommunikation und Lyrik wurden in der Folge weiter ausgetestet. So trug Hugo Ball am 14. Juli 1916, jenem großen dadaistischen Abend in Zürich, sein legendär gewordenes Lautgedicht $O$ Gadji Beri Bimba vor, womit die Semantik im reinen Lautgedicht scheinbar gegen Null gefahren wurde. Hier waren nicht mehr nur die Wörter ,befreit‘. Die dadaistische Lyrik wurde zu einer Grenzerfahrung: Sie verstand sich als Lyrik über alle Grenzen und als Lyrik der Grenze insgesamt. Genau an diesem Punkte erreichen wir die absolute Nähe zu kultischen Beschwörungsformeln, zum Rituellen, zum Irrationalen und Mythischen, das den Menschen auf neue, auf eine weiter gespannte Weise wieder in den Kosmos integriert. Die Nähe zur Psychoanalyse Sigmund Freuds ist immer wieder mit Händen greifbar, so etwa auch, wenn wenig später André Breton hieraus die Konsequenzen zieht und fordert, man müsse das Murmeln des Unbewussten hörbar machen. Roland Barthes wird in den ausgehenden sechziger Jahren vom „Rauschen der Sprache“ sprechen, ganz einer deterministischen Semantik einer Sprache entwunden, die er übrigens des Faschismus bezichtigte. Die Beziehungen zwischen den historischen Avantgarden und den Theorie-Avantgarden der zweiten Hälfte des 20. Jahrhunderts sind Legion.

Die Dadaisten hatten freilich nicht nur das Murmeln des Unbewussten, sondern auch eine Veränderung ihres zeitgeschichtlichen und politischen wie kulturellen Kontexts im Sinn. Ihre Sinnverweigerung hat nicht nur Methode, sondern macht auch noch Sinn. Sie ist die bis an ihre Grenzen getriebene Dichte des Gedichts, Anklage des Menschen gegenüber einer sinnlos gewordenen Welt, in welcher sich nicht im Umgang mit einer zu häufig in der bürgerlichen Gesellschaft missbrauchten Sprache Sinn herstellen lässt. Die Sprache selbst musste radikal verändert werden, revolutionär umgestaltet werden: Sie musste, in einem Wort, explodieren!

Das Schwinden des Sinns und das Schwinden der Worte ist im Übrigen nicht nur ein Phänomen der Avantgarde. Während die Graffiti meiner Studentenzeit konkrete Forderungen formulierten, zu Aktionen aufriefen oder einfach mit Worten spielten, - gerne erinnere ich mich etwa an ein Graffiti an der Universität Freiburg: „Ich hatte schlechte Lehrer, das war eine gute Schule!“ - fehlen den Graffiti unserer Tage seit langen Jahren die Worte. Es sind Spiele mit Buchstaben, die graphisiert werden, in reine Zeichen verwandelt, die ihrer eigenen Bedeutsamkeit im Kontext verlustig gegangen sind und darauf hinweisen. Es sind bisweilen auch Buchstaben in Freiheit, nicht mehr nur Worte, und sie verweigern sich auf einer unmittelbaren Ebene direkter Kommunikation und Sinnzuweisung. 
Keineswegs möchte ich damit alle Schmierereien in den Rang eines (avantgardistischen) Kunstwerks heben! Aber auch hier zeigt sich, dass bestimmte Verfahren und Logiken der Avantgarde nicht einfach ausgestorben sind oder kurzerhand in die Werbung emigrierten. Sie sind präsent, in den unterschiedlichsten Formen, und ein gewisses provokatorisches Potenzial ist ihnen noch immer eigen, auch wenn sich manche Epigonen kreativer Versprüher dieses Erbes mit Sicherheit nicht mehr bewusst sind. So wie die dadaistischen Gedichte bisweilen Verse ohne Worte waren, so sind die Graffiti unserer Tage Inschriften ohne Worte, Forderungen ohne Thesen, die auf die Grenzen des Kommunizierbaren hinweisen. Sie bilden eine Ausdrucksform, welche auf Restbestände oder Residua von Inhalten aufmerksam macht, die in unserer Gesellschaft nicht mehr kommunizierbar zu sein scheinen.

So lassen sie sich keineswegs nur auf einen Kampf zwischen Sprühern oder Sprayern und Malern im Sinne von Anstreichern reduzieren, die Hauswände wieder übertünchen. Sie sind gesellschaftliche Symptome, denen eine gewisse künstlerische Intention innewohnt, die freilich von einer Lebenspraxis und mehr noch von einem Imitationskult überlagert wird. Auch sie sind Ausdrucksformen von Lebenswissen. Dadaistisch sind sie nicht, wenn auch vom Dadaismus mitgeprägt. Sprachlosigkeit äußert sich entweder in der Lautlosigkeit oder im Schrei. Die Schriftlosigkeit scheint sich des Graffitis bedienen zu können. Auch ihnen wohnt eine Ästhetik der Negation - um mit Theodor W. Adorno zu sprechen inne.

Ich möchte an dieser Stelle die bereits geknüpften Verbindungsstellen zwischen Dadaismus und Surrealismus nicht weiter entwickeln und die Entfaltung der historischen Avantgarden in ihrer zentralen Linie nicht weiterverfolgen, sondern jetzt - wie bereits zu Beginn der Vorlesung angekündigt - eine Europa übersteigende Dimension in unsere Reflexionen zu den historischen Avantgarden einbinden. Diese veränderte Perspektive wird Rückwirkungen haben auf unseren Blick auf die unterschiedlichsten Phänomene des Surrealismus weltweit. So werden wir besser verstehen können, inwieweit die historischen Avantgarden eine gemeinsame Dimension besaßen und zugleich eine Heterogenität aufwiesen, die es - entgegen vieler Handbücher zur Avantgarde - im Grunde nicht länger ermöglicht, von der Existenz einer einzigen Entwicklungslinie der Avantgarden zu sprechen. 